\title{
Silver Nanoparticles
}

\author{
Hassan Korbekandi ${ }^{1}$ and Siavash Iravani ${ }^{2}$ \\ ${ }^{1}$ Genetics and Molecular Biology Department, School of Medicine, \\ Isfahan University of Medical Sciences \\ ${ }^{2}$ School of Pharmacy and Pharmaceutical Science, \\ Isfahan University of Medical Sciences
}

Iran

\section{Introduction}

Nanotechnology is an important field of modern research dealing with design, synthesis, and manipulation of particles structure ranging from approximately 1-100 nm. Tremendous growth in this emerging technology has opened novel fundamental and applied frontiers, including the synthesis of nanoscale materials and exploration or utilization of their exotic physicochemical and optoelectronic properties. Nanotechnology is rapidly gaining importance in a number of areas such as health care, cosmetics, food and feed, environmental health, mechanics, optics, biomedical sciences, chemical industries, electronics, space industries, drug-gene delivery, energy science, optoelectronics, catalysis, reorography, single electron transistors, light emitters, nonlinear optical devices, and photoelectrochemical applications (Colvin et al. 1994; Wang and Herron 1991; Schmid 1992; Hoffman et al. 1992; Hamilton and Baetzold 1979; Mansur et al. 1995).

Silver nanoparticles are of interest because of the unique properties (e.g., size and shape depending optical, electrical, and magnetic properties) which can be incorporated into antimicrobial applications, biosensor materials, composite fibers, cryogenic superconducting materials, cosmetic products, and electronic components. Several physical and chemical methods have been used for synthesizing and stabilizing silver nanoparticles (Senapati 2005; Klaus-Joerger et al. 2001). The most popular chemical approaches, including chemical reduction using a variety of organic and inorganic reducing agents, electrochemical techniques, physicochemical reduction, and radiolysis are widely used for the synthesis of silver nanoparticles. Recently, nanoparticle synthesis is among the most interesting scientific areas of inquiry, and there is growing attention to produce nanoparticles using environmentally friendly methods (green chemistry). Green synthesis approaches include mixed-valence polyoxometalates, polysaccharides, Tollens, biological, and irradiation method which have advantages over conventional methods involving chemical agents associated with environmental toxicity. This chapter presents an overview of silver nanoparticle preparation by physical, chemical, and green synthesis approaches. The aim of this chapter is, therefore, to reflect on the current state and future prospects, especially the potentials and limitations of the above mentioned techniques for industries. Moreover, we discuss the applications of silver nanoparticles and their incorporation into other materials, the mechanistic aspects of the antimicrobial effects of silver nanoparticles. 


\section{Synthesis of silver nanoparticles}

\subsection{Physical approaches}

Most important physical approaches include evaporation-condensation and laser ablation. Various metal nanoparticles such as silver, gold, lead sulfide, cadmium sulfide, and fullerene have previously been synthesized using the evaporation-condensation method. The absence of solvent contamination in the prepared thin films and the uniformity of nanoparticles distribution are the advantages of physical approaches in comparison with chemical processes. Physical synthesis of silver nanoparticles using a tube furnace at atmospheric pressure has some disadvantages, for example, tube furnace occupies a large space, consumes a great amount of energy while raising the environmental temperature around the source material, and requires a great deal of time to achieve thermal stability. Moreover, a typical tube furnace requires power consumption of more than several kilowatts and a preheating time of several tens of minutes to reach a stable operating temperature (Kruis et al. 2000; Magnusson et al. 1999). It was demonstrated that silver nanoparticles could be synthesized via a small ceramic heater with a local heating source (Jung et al. 2006). The evaporated vapor can cool at a suitable rapid rate, because the temperature gradient in the vicinity of the heater surface is very steep in comparison with that of a tube furnace. This makes possible the formation of small nanoparticles in high concentration. This physical method can be useful as a nanoparticle generator for long-term experiments for inhalation toxicity studies, and as a calibration device for nanoparticle measurement equipment (Jung et al. 2006).

Silver nanoparticles could be synthesized by laser ablation of metallic bulk materials in solution (Mafune et al. 2000; Mafune et al. 2001; Kabashin and Meunier 2003; Sylvestre et al. 2004; Dolgaev et al. 2002). The ablation efficiency and the characteristics of produced nanosilver particles depend upon many factors such as the wavelength of the laser impinging the metallic target, the duration of the laser pulses (in the femto-, pico- and nanosecond regime), the laser fluence, the ablation time duration and the effective liquid medium, with or without the presence of surfactants (Kim et al. 2005; Link et al. 2000; Tarasenko et al. 2006; Kawasaki and Nishimura 2006). One important advantage of laser ablation technique compared to other methods for production of metal colloids is the absence of chemical reagents in solutions. Therefore, pure and uncontaminated metal colloids for further applications can be prepared by this technique (Tsuji et al. 2002). Silver nanospheroids (20$50 \mathrm{~nm}$ ) were prepared by laser ablation in water with femtosecond laser pulses at $800 \mathrm{~nm}$ (Tsuji et al. 2003). The formation efficiency and the size of colloidal particles were compared with those of colloidal particles prepared by nanosecond laser pulses. The results revealed the formation efficiency for femtosecond pulses was significantly lower than that for nanosecond pulses. The size of colloids prepared by femtosecond pulses were less dispersed than that of colloids prepared by nanosecond pulses. Furthermore, it was found that the ablation efficiency for femtosecond ablation in water was lower than that in air, while, in the case of nanosecond pulses, the ablation efficiency was similar in both water and air.

\subsection{Chemical approaches}

The most common approach for synthesis of silver nanoparticles is chemical reduction by organic and inorganic reducing agents. In general, different reducing agents such as sodium 
citrate, ascorbate, sodium borohydride $\left(\mathrm{NaBH}_{4}\right)$, elemental hydrogen, polyol process, Tollens reagent, $\mathrm{N}, \mathrm{N}$-dimethylformamide (DMF), and poly (ethylene glycol)-block copolymers are used for reduction of silver ions $\left(\mathrm{Ag}^{+}\right)$in aqueous or non-aqueous solutions. The aforementioned reducing agents reduce silver ions $\left(\mathrm{Ag}^{+}\right)$and lead to the formation of metallic silver $\left(\mathrm{Ag}^{0}\right)$, which is followed by agglomeration into oligomeric clusters. These clusters eventually lead to formation of metallic colloidal silver particles (Wiley et al. 2005; Evanoff and Chumanov 2004; Merga et al. 2007). It is important to use protective agents to stabilize dispersive nanoparticles during the course of metal nanoparticle preparation, and protect the nanoparticles that can be absorbed on or bind onto nanoparticle surfaces, avoiding their agglomeration (Oliveira et al. 2005). The presence of surfactants comprising functionalities (e.g., thiols, amines, acids, and alcohols) for interactions with particle surfaces can stabilize particle growth, and protect particles from sedimentation, agglomeration, or losing their surface properties. Polymeric compounds such as poly(vinyl alcohol), poly(vinylpyrrolidone), poly(ethylene glycol), poly(methacrylic acid), and polymethylmethacrylate have been reported to be effective protective agents to stabilize nanoparticles. In one study, Oliveira et al. (Oliveira et al. 2005) prepared dodecanethiolcapped silver nanoparticles, based on Brust procedure (Brust and Kiely 2002), based on a phase transfer of an $\mathrm{Au}^{3+}$ complex from aqueous to organic phase in a two-phase liquidliquid system, followed by a reduction with sodium borohydride in the presence of dodecanethiol as a stabilizing agent, binding onto the nanoparticles surfaces, thereby avoiding their aggregation and making them soluble in certain solvents. They reported that small changes in synthetic factors lead to dramatic modifications in nanoparticle structure, average size, size distribution width, stability and self-assembly patterns. Zhang et al. (2008) used a hyperbranched poly(methylene bisacrylamide aminoethyl piperazine) with terminal dimethylamine groups (HPAMAM-N $\left.\left(\mathrm{CH}_{3}\right)_{2}\right)$ to produce colloids of silver. The amide moieties, piperazine rings, tertiary amine groups and the hyper-branched structure in HPAMAM-N $\left(\mathrm{CH}_{3}\right)_{2}$ are important to its effective stabilizing and reducing abilities.

Uniform and size controllable silver nanoparticles can be synthesized using micro-emulsion techniques. The nanoparticles preparation in two-phase aqueous organic systems is based on the initial spatial separation of reactants (metal precursor and reducing agent) in two immiscible phases. The interface between the two liquids and the intensity of inter-phase transport between two phases, which is mediated by a quaternary alkyl-ammonium salt, affect the rate of interactions between metal precursors and reducing agents. Metal clusters formed at the interface are stabilized, due to their surface being coated with stabilizer molecules occurring in the non-polar aqueous medium, and transferred to the organic medium by the inter-phase transporter (Krutyakov et al. 2008). One of the major disadvantages of this method is the use of highly deleterious organic solvents. Thus large amounts of surfactant and organic solvent must be separated and removed from the final product. For instance, Zhang et al. (2007) used dodecane as an oily phase (a low deleterious and even nontoxic solvent), but there was no need to separate the prepared silver solution from the reaction mixture. On other hand, colloidal nanoparticles prepared in nonaqueous media for conductive inks are well-dispersed in a low vapor pressure organic solvent, to readily wet the surface of the polymeric substrate without any aggregation. These advantages can also be found in the applications of metal nanoparticles as catalysts to catalyze most organic reactions, which have been conducted in non-polar solvents. It is very 
important to transfer nanometal particles to different physicochemical environments in practical applications (Cozzoli et al. 2004).

A simple and effective method, UV-initiated photoreduction, has been reported for synthesis of silver nanoparticles in the presence of citrate, polyvinylpyrrolidone, poly(acrylic acid), and collagen. For instance, Huang and Yang produced silver nanoparticles via the photoreduction of silver nitrate in layered inorganic laponite clay suspensions which served as a stabilizing agent for the prevention of nanoparticles aggregation. The properties of the produced nanoparticles were studied as a function of UV irradiation time. Bimodal size distribution and relatively large silver nanoparticles were obtained when irradiated under UV for $3 \mathrm{~h}$. Further irradiation disintegrated the silver nanoparticles into smaller sizes with a single distribution mode until a relatively stable size and size distribution was obtained (Huang and Yang 2008). Silver nanoparticles (nanosphere, nanowire, and dendrite) have been prepared by an ultraviolet irradiation photoreduction technique at room temperature using poly(vinylalcohol) (as protecting and stabilizing agent). Concentration of both poly(vinylalcohol) and silver nitrate played significant role in the growth of the nanorods and dendrites (Zhou et al. 1999). Sonoelectrochemistry technique utilizes ultrasonic power primarily to manipulate the material mechanically. The pulsed sonoelectrochemical synthetic method involves alternating sonic and electric pulses, and electrolyte composition plays a crucial role in shape formation (Socol et al. 2002). It was reported that silver nanospheres could be prepared by sonoelectrochemical reduction using a complexing agent, nitrilotriacetate to avoid aggregation (Socol et al. 2002).

Nano-sized silver particles with an average size of $8 \mathrm{~nm}$ were prepared by photoinduced reduction using poly(styrene sulfonate)/poly(allylamine hydrochloride) polyelectrolyte capsules as microreactors (Shchukin et al. 2003). Moreover, it was demonstrated that the photoinduced method could be used for converting silver nanospheres into triangular silver nanocrystals (nanoprisms) with desired edge lengths in the range of 30-120 nm (Jin et al. 2003). The particle growth process was controlled using dual-beam illumination of nanoparticles. Citrate and poly(styrene sulfonate) were used as stabilizing agents. In another study, silver nanoparticles were prepared through a very fast reduction of $\mathrm{Ag}^{+}$by aaminoalkyl radicals generated from hydrogen abstraction toward an aliphatic amine by the excited triplet state of 2-substituted thioxanthone series $\left(\mathrm{TX}-\mathrm{O}-\mathrm{CH}_{2}-\mathrm{COO}^{-}\right.$and $\mathrm{TX}-\mathrm{S}-\mathrm{CH}_{2}-\mathrm{COO}^{-}$). The quantum yield of this prior reaction was tuned by a substituent effect on the thioxanthones, and led to a kinetic control of the conversion of $\mathrm{Ag}^{+}$to $\mathrm{Ag}(0)$ (Malval et al. 2010).

Electrochemical synthetic method can be used to synthesize silver nanoparticles. It is possible to control particle size by adjusting the electrolysis parameters and to improve homogeneity of silver nanoparticles by changing the composition of the electrolytic solutions. Polyphenylpyrrole-coated silver nanospheroids $(3-20 \mathrm{~nm})$ were synthesized by electrochemical reduction at the liquid/liquid interface. This nano-compound was prepared by transferring the silver metal ion from the aqueous phase to the organic phase, where it reacted with pyrrole monomer (Johans et al. 2002). In another study, monodisperse silver nanospheroids (1-18 $\mathrm{nm}$ ) were synthesized by electrochemical reduction inside or outside zeolite crystals according to the silver exchange degree of the compact zeolite film modified electrodes (Zhang et al. 2002). Furthermore, spherical silver nanoparticles (10-20 nm) with 
narrow size distributions were conveniently synthesized in an aqueous solution by an electrochemical method (Ma et al. 2004). Poly N-vinylpyrrolidone was chosen as the stabilizer for the silver clusters in this study. Poly N-vinylpyrrolidone protects nanoparticles from agglomeration, significantly reduces silver deposition rate, and promotes silver nucleation and silver particle formation rate. Application of rotating platinum cathode effectively solves the technological difficulty of rapidly transferring metallic nanoparticles from the cathode vicinity to bulk solution, avoiding the occurrence of flocculates in vicinity of the cathode, and ensures monodispersity of particles. The addition of sodium dodecyl benzene sulfonate to the electrolyte improved the particle size and particle size distribution of the silver nanoparticles (Ma et al. 2004).

Silver nanoparticles can be synthesized by using a variety of irradiation methods. Laser irradiation of an aqueous solution of silver salt and surfactant can produce silver nanoparticles with a well defined shape and size distribution (Abid et al. 2002). Furthermore, the laser was used in a photo-sensitization synthetic method of making silver nanoparticles using benzophenone. Low laser powers at short irradiation times produced silver nanoparticles of approximately $20 \mathrm{~nm}$, while an increased irradiation power produced nanoparticles of approximately $5 \mathrm{~nm}$. Laser and mercury lamp can be used as light sources for the production of silver nanoparticles (Eutis et al. 2005). In visible light irradiation studies, the photo-sensitized growth of silver nanoparticles using thiophene (sensitizing dye) and silver nanoparticle formation by illumination of $\mathrm{Ag}\left(\mathrm{NH}_{3}\right)^{+}$in ethanol has been accomplished (Sudeep and Kamat 2005; Zhang et al. 2003).

Microwave assisted synthesis is a promising method for the synthesis of silver nanoparticles. It was reported that silver nanoparticles could be synthesized by a microwave-assisted synthesis method employing carboxymethyl cellulose sodium as a reducing and stabilizing agent. The size of the resulting particles depended on the concentration of sodium carboxymethyl cellulose and silver nitrate. The produced nanoparticles were uniform and stable, and were stable at room temperature for 2 months without any visible change (Chen et al. 2008). The production of silver nanoparticles in the presence of $\mathrm{Pt}$ seeds, polyvinyl pyrrolidine and ethylene glycol was also reported (Navaladian et al. 2008). Additionally, starch has been employed as a template and reducing agent for the synthesis of silver nanoparticles with an average size of $12 \mathrm{~nm}$, using a microwave-assisted synthetic method. Starch functions as a template, preventing the aggregation of the produced silver nanoparticles (Sreeram et al. 2008). Microwaves in combination with polyol process were applied in the synthesis of silver nanospheroids using ethylene glycol and poly $\mathrm{N}$-vinylpyrrolidone as reducing and stabilizing agents, respectively (Komarneni et al. 2002). In a typical polyol process inorganic salt is reduced by the polyol (e.g., ethylene glycol which serves as both a solvent and a reducing agent) at a high temperature. Yin et al. (Yin et al. 2004) reported that large-scale and size-controlled silver nanoparticles could be rapidly synthesized under microwave irradiation from an aqueous solution of silver nitrate and trisodium citrate in the presence of formaldehyde as a reducing agent. Size and size distribution of the produced silver nanoparticles are strongly dependent on the states of silver cations in the initial reaction solution. Silver nanoparticles with different shapes can be synthesized by microwave irradiation of a silver nitrateethylene-glycol- $\mathrm{H}_{2}\left[\mathrm{PtCl}_{6}\right]$-poly(vinylpyrrolidone) solution within 3 min (Tsuji et al. 2008). Moreover, the use of microwave irradiation to produce monodispersed silver nanoparticles 
using basic amino acids (as reducing agents) and soluble starch (as a protecting agent) has been reported (Hu et al. 2008). Radiolysis of silver ions in ethylene glycol, in order to synthesize silver nanoparticles, was also reported (Soroushian et al. 2005). Moreover, silver nanoparticles supported on silica aero-gel were produced using gamma radiolysis. The produced silver clusters were stable in the 2-9 $\mathrm{pH}$ range and started agglomeration at $\mathrm{pH}>9$ (Ramnami et al. 2007). Oligochitosan as a stabilizer can be used in a preparation of silver nanoparticles by gamma radiation. It was reported that stable silver nanoparticles (5$15 \mathrm{~nm}$ ) were synthesized in a 1.8-9.0 $\mathrm{pH}$ range using this method (Long et al. 2007). Silver nanoparticles $(4-5 \mathrm{~nm})$ were also synthesized by $\gamma$-ray irradiation of acetic water solutions containing silver nitrate and chitosan (Cheng et al. 2007). In another study, silver nanospheroids (1-4 nm) were produced by $\gamma$-ray irradiation of a silver solution in optically transparent inorganic mesoporous silica. Reduction of silver ions within the matrix is brought about by hydrated electrons and hydroalkyl radicals generated during the radiolysis of a 2-propanol solution. The nanoparticles produced within the silica matrix were stable in the presence of oxygen for at least several months (Hornebecq et al. 2003). Moreover, silver nanoparticles $(60-200 \mathrm{~nm})$ have been produced by irradiating a solution, prepared by mixing silver nitrate and poly-vinyl-alcohol, with $6 \mathrm{MeV}$ electrons (Bogle et al. 2006). A pulse radiolysis technique has been applied to study the reactions of inorganic and organic species in silver nanoparticle synthesis, to understand the factors controlling the shape and size of the nanoparticles synthesized by a common reduction method using citrate ions (as reducing and stabilizing agents) (Pillai and Kamat 2004), and to demonstrate the role of phenol derivatives in the formation of silver nanoparticles by the reduction of silver ions with dihydroxy benzene (Jacob et al. 2008). Dihydroxy benzene could be also used to reduce silver ions to synthesize stable silver nanoparticles (with an average size of $30 \mathrm{~nm}$ ) in air-saturated aqueous solutions (Jacob et al. 2008).

In polysaccharide method, silver nanoparticles were prepared using water as an environmentally-friendly solvent and polysaccharides as capping/reducing agents. For instance, the synthesis of starch-silver nanoparticles was carried out with starch (as a capping agent) and $\beta$-D-glucose (as a reducing agent) in a gently heated system (Raveendran et al. 2003). The binding interactions between starch and produced silver nanoparticles were weak and could be reversible at higher temperatures, allowing for the separation of the synthesized nanoparticles. In dual polysaccharide function, silver nanoparticles were synthesized by the reduction of silver ions inside nanoscopic starch templates (Raveendran et al. 2003, 2005). The extensive network of hydrogen bands in templates provided surface passivation or protection against nanoparticle aggregation. Green synthesis of silver nanoparticles using negatively charged heparin (reducing/stabilizing agent and nucleation controller) was also reported by heating a solution of silver nitrate and heparin to $70{ }^{\circ} \mathrm{C}$ for approximately $8 \mathrm{~h}$ (Huang and Yang 2004). Transmission electron microscopy (TEM) micrographs demonstrated an increase in particle size of silver nanoparticles with increased concentrations of silver nitrate (as the substrate) and heparin. Moreover, changes in the heparin concentration influenced the morphology and size of silver nanoparticles. The synthesized silver nanoparticles were highly stable, and showed no signs of aggregation after two months (Huang and Yang 2004). In another study, stable silver nanoparticles $(10-34 \mathrm{~nm})$ were synthesized by autoclaving a solution of silver nitrate (as the substrate) and starch (as a capping/reducing agent) at 15 psi and $121^{\circ} \mathrm{C}$ for 5 min (Vigneshwaran et al. 2006b). These nanoparticles were stable in solution for three 
months at approximately $25^{\circ} \mathrm{C}$. Smaller silver nanoparticles $(\leq 10 \mathrm{~nm})$ were synthesized by mixing two solutions of silver nitrate containing starch (as a capping agent), and $\mathrm{NaOH}$ solutions containing glucose (as a reducing agent) in a spinning disk reactor with a reaction time of less than $10 \mathrm{~min}$ (Tai et al. 2008).

Recently, a simple one-step process, Tollens method, has been used for the synthesis of silver nanoparticles with a controlled size. This green synthesis technique involves the reduction of $\mathrm{Ag}\left(\mathrm{NH}_{3}\right)_{2}{ }^{+}$(as a Tollens reagent) by an aldehyde (Yin et al. 2002). In the modified Tollens procedure, silver ions are reduced by saccharides in the presence of ammonia, yielding silver nanoparticle films (50-200 nm), silver hydrosols $(20-50 \mathrm{~nm})$ and silver nanoparticles of different shapes. In this method, the concentration of ammonia and the nature of the reducing agent play an important role in controlling size and morphology of the silver nanoparticles. It was revealed that the smallest particles were formed at the lowest ammonia concentration. Glucose and the lowest ammonia concentration $(5 \mathrm{mM})$ resulted in the smallest average particle size of $57 \mathrm{~nm}$ with an intense maximum surface plasmon absorbance at $420 \mathrm{~nm}$. Moreover, an increase in $\mathrm{NH}_{3}$ from $0.005 \mathrm{M}$ to $0.2 \mathrm{M}$ resulted in a simultaneous increase in particle size and polydispersity (Kvítek et al. 2005). Silver nanoparticles with controllable sizes were synthesized by reduction of $\left[\mathrm{Ag}\left(\mathrm{NH}_{3}\right)_{2}\right]^{+}$ with glucose, galactose, maltose, and lactose (Panacek et al. 2006). The nanoparticle synthesis was carried out at various ammonia concentrations $(0.005-0.20 \mathrm{M})$ and $\mathrm{pH}$ conditions (11.5-13.0), resulting in average particle sizes of $25-450 \mathrm{~nm}$. The particle size was increased by increasing $\left(\mathrm{NH}_{3}\right)$, and the difference in the structure of the reducing agent (monosaccharides and disaccharides) and $\mathrm{pH}$ (particles obtained at $\mathrm{pH} 11.5$ were smaller than those at $\mathrm{pH}$ 12.5) influenced the particle size. Polydispersity also decreased in response to decreases the $\mathrm{pH}$. Produced silver nanoparticles were stabilized and protected by sodium dodecyl sulfate (SDS), polyoxyethylenesorbitane monooleate (Tween 80), and polyvinylpyrrolidone (PVP 360) (Kvitek et al. 2008; Soukupova et al. 2008).

Silver, gold, palladium, and platinum nanoparticles can be produced at room temperature, as a result of simply mixing the corresponding metal ions with reduced polyoxometalates which served as reducing and stabilizing agents. Polyoxometalates are soluble in water and have the capability of undergoing stepwise, multielectron redox reactions without disturbing their structure. It was demonstrated that silver nanoparticles were produced by illuminating a deaerated solution of polyoxometalate/S/ $\mathrm{Ag}^{+}$(polyoxometalate: $\left[\mathrm{PW}_{12} \mathrm{O}_{40}\right]^{3}$, $\left[\mathrm{SiW}_{12} \mathrm{O}_{40}\right]^{4-}$; S:propan-2-ol or 2,4-dichlorophenol) (Troupis et al. 2002). Furthermore, green chemistry-type one-step synthesis and stabilization of silver nanostructures with $\mathrm{Mo}^{\mathrm{V}}-\mathrm{Mo}^{\mathrm{VI}}$ mixed-valence polyoxometalates in water at room temperature has been reported (Zhang et al. 2007).

\subsection{Biological approaches}

In recent years, the development of efficient green chemistry methods employing natural reducing, capping, and stabilizing agents to prepare silver nanoparticles with desired morphology and size have become a major focus of researchers. Biological methods can be used to synthesize silver nanoparticles without the use of any harsh, toxic and expensive chemical substances (Ahmad et al. 2003a; Shankar et al. 2004; Ankamwar et al. 2005; Huang et al. 2007). The bioreduction of metal ions by combinations of biomolecules found in the extracts of certain organisms (e.g., enzymes/proteins, amino acids, polysaccharides, and 
vitamins) is environmentally benign, yet chemically complex. Many studies have reported successful synthesis of silver nanoparticle using organisms (microorganisms and biological systems) (Korbekandi et al. 2009; Sastry et al. 2003; Iravani 2011). For instance, we demonstrated the bioreductive synthesis of silver nanoparticles using F. oxysporum (Figure 1). In this section, most of the organisms used in green synthesis of silver nanoparticles are shown.

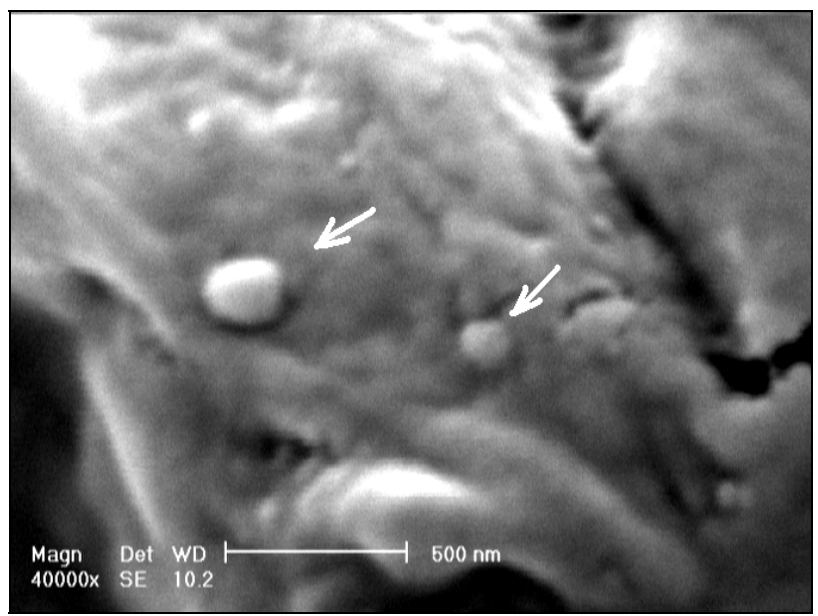

Fig. 1. SEM micrograph recorded from silver nanoparticles produced by reaction of $\mathrm{AgNO}_{3}$ solution $(1 \mathrm{mM})$ with F. oxysporum biomass.

\subsubsection{Synthesis of silver nanoparticles by bacteria}

It was reported that highly stable silver nanoparticles $(40 \mathrm{~nm})$ could be synthesized by bioreduction of aqueous silver ions with a culture supernatant of nonpathogenic bacterium, Bacillus licheniformis (Kalishwaralal et al. 2008b). Moreover, well-dispersed silver nanocrystals $(50 \mathrm{~nm})$ were synthesized using the bacterium Bacillus licheniformis (Kalishwaralal et al. 2008a). Saifuddin et al. (Saifuddin et al. 2009) have described a novel combinational synthesis approach for the formation of silver nanoparticles by using a combination of culture supernatant of $B$. subtilis and microwave irradiation in water. They reported the extracellular biosynthesis of monodispersed Ag nanoparticles (5-50 nm) using supernatants of $B$. subtilis, but in order to increase the rate of reaction and reduce the aggregation of the produced nanoparticles, they used microwave radiation which might provide uniform heating around the nanoparticles and could assist the digestive ripening of particles with no aggregation.

Silver nanocrystals of different compositions were successfully synthesized by Pseudomonas stutzeri AG259 (Klaus et al. 1999). The silver-resistant bacterial strain, Pseudomonas stutzeri AG259, isolated from a silver mine, accumulated silver nanoparticles intracellularly, along with some silver sulfide, ranging in size from 35 to $46 \mathrm{~nm}$ (Slawson et al. 1992). Larger particles were formed when $P$. stutzeri AG259 challenged with high concentrations of silver ions during culturing, resulted intracellular formation of silver nanoparticles, ranging in size 
from a few $\mathrm{nm}$ to $200 \mathrm{~nm}$ (Klaus-Joerger et al. 2001; Klaus et al. 1999). P. stutzeri AG259 detoxificated silver through its precipitation in the periplasmic space and its reduction to elemental silver with a variety of crystal typologies, such as hexagons and equilateral triangles, as well as three different types of particles: elemental crystalline silver, monoclinic silver sulfide acanthite $\left(\mathrm{Ag}_{2} \mathrm{~S}\right)$, and a further undetermined structure (Klaus et al. 1999). The periplasmic space limited the thickness of the crystals, but not their width, which could be rather large (100-200 nm) (Klaus-Joerger et al. 2001). In another study, rapid biosynthesis of metallic nanoparticles of silver using the reduction of aqueous $\mathrm{Ag}^{+}$ions by culture supernatants of Klebsiella pneumonia, E. coli, and Enterobacter cloacae (Enterobacteriacae) was reported (Shahverdi et al. 2007). The synthetic process was quite fast and silver nanoparticles were formed within $5 \mathrm{~min}$ of silver ions coming in contact with the cell filtrate. It seems that nitroreductase enzymes might be responsible for bioreduction of silver ions. It was also reported that visible-light emission could significantly increase synthesis of silver nanoparticles (1-6 nm) by culture supernatants of K. pneumoniae (Mokhtari et al. 2009). Monodispersed and stable silver nanoparticles were also successfully synthesized with bioreduction of $\left[\mathrm{Ag}\left(\mathrm{NH}_{3}\right)_{2}\right]^{+}$using Aeromonas sp. SH10 and Corynebacterium sp. SH09 (Mouxing et al. 2006). It was speculated that $\left[\mathrm{Ag}\left(\mathrm{NH}_{3}\right)_{2}\right]+$ first reacted with $\mathrm{OH}^{-}$to form $\mathrm{Ag}_{2} \mathrm{O}$, which was then metabolized independently and reduced to silver nanoparticles by the biomass.

Lactobacillus strains, when exposed to silver ions, resulted in biosynthesis of nanoparticles within the bacterial cells (Nair and Pradeep 2002). It has been reported that exposure of lactic acid bacteria present in the whey of buttermilk to mixtures of silver ions could be used to grow nanoparticles of silver. The nucleation of silver nanoparticles occurred on the cell surface through sugars and enzymes in the cell wall, and then the metal nuclei were transported into the cell where they aggregated and grew to larger-sized particles.

\subsubsection{Synthesis of silver nanoparticles by fungi}

Silver nanoparticles $(5-50 \mathrm{~nm})$ could be synthesized extracellularly using Fusarium oxysporum, with no evidence of flocculation of the particles even a month after the reaction (Ahmad et al. 2003a). The long-term stability of the nanoparticle solution might be due to the stabilization of the silver particles by proteins. The morphology of nanoparticles was highly variable, with generally spherical and occasionally triangular shapes observed in the micrographs. Silver nanoparticles have been reported to interact strongly with proteins including cytochrome $c(\mathrm{Cc})$. This protein could be self-assembled on citrate-reduced silver colloid surface (Macdonald and Smith 1996). Interestingly, adsorption of (Cc)-coated colloidal Au nanoparticles onto aggregated colloidal Ag resulted Ag: Cc: Au nanoparticle conjugate (Keating et al. 1998). In UV-vis spectra from the reaction mixture after $72 \mathrm{~h}$, the presence of an absorption band at ca. $270 \mathrm{~nm}$ might be due to electronic excitations in tryptophan and tyrosine residues in the proteins. In F. oxysporum, the bioreduction of silver ions was attributed to an enzymatic process involving NADH-dependent reductase (Ahmad et al. 2003b). The exposure of silver ions to F. oxysporum, resulted in release of nitrate reductase and subsequent formation of highly stable silver nanoparticles in solution (Kumar et al. 2007). The secreted enzyme was found to be dependent on NADH cofactor. They mentioned high stability of nanoparticles in solution was due to capping of particles by 
release of capping proteins by F. oxysporum. Stability of the capping protein was found to be $\mathrm{pH}$ dependent. At higher $\mathrm{pH}$ values $(>12)$, the nanoparticles in solution remained stable, while they aggregated at lower $\mathrm{pH}$ values $(<2)$ as the protein was denatured. Kumar et al. (Kumar et al. 2007) have demonstrated enzymatic synthesis of silver nanoparticles with different chemical compositions, sizes and morphologies, using a-NADPH-dependent nitrate reductase purified from F. oxysporum and phytochelatin, in vitro. Silver ions were reduced in the presence of nitrate reductase, leading to formation of a stable silver hydrosol $10-25 \mathrm{~nm}$ in diameter and stabilized by the capping peptide. Use of a specific enzyme in in vitro synthesis of nanoparticles showed interesting advantages. This would eliminate the downstream processing required for the use of these nanoparticles in homogeneous catalysis and other applications such as non-linear optics. The biggest advantage of this protocol based on purified enzyme was the development of a new approach for green synthesis of nanomaterials over a range of chemical compositions and shapes without possible aggregation. Ingle et al. (Ingle et al. 2008) demonstrated the potential ability of Fusarium acuminatum Ell. and Ev. (USM-3793) cell extracts in biosynthesis of silver nanoparticles. The nanoparticles produced within 15-20 minutes and were spherical with a broad size distribution in the range of $5-40 \mathrm{~nm}$ with the average diameter of $13 \mathrm{~nm}$. A nitrate-dependent reductase enzyme might act as the reducing agent. The white rot fungus, Phanerochaete chrysosporium, also reduced silver ions to form nano-silver particles (Vigneshwaran et al. 2006a). The most dominant morphology was pyramidal shape, in different sizes, but hexagonal structures were also observed. Possible involvement of proteins in synthesizing silver nanoparticles was observed in Plectonema boryanum UTEX 485 (a filamentous cyanobacterium) (Lengke et al. 2007).

Stable silver nanoparticles could be achieved by using Aspergillus flavus (Vigneshwaran et al. 2007). These nanoparticles were found to be stable in water for more than 3 months with no significant aggregation because of surface binding of stabilizing materials secreted by the fungus (Vigneshwaran et al. 2007). Extracellular biosynthesis of silver nanoparticles using Aspergillus fumigatus (a ubiquitous saprophytic mold) has also been investigated (Bhainsa and D'Souza 2006). The resulted TEM micrograph showed well-dispersed silver nanoparticles $(5-25 \mathrm{~nm})$ with variable shapes. Most of them were spherical in nature with some others having occasionally triangular shapes (Bhainsa and D'Souza 2006). Compared to intracellular biosynthesis of nanoparticles; extracellular synthesis could be developed as a simple and cheap method because of uncomplicated downstream processing and handling of biomasses.

The extracellular filtrate of Cladosporium cladosporioides biomass was used to synthesize silver nanoparticles (Balaji et al. 2009). It was suggested that proteins, organic acids and polysaccharides released by $C$. cladosporioides were responsible for formation of spherical crystalline silver nanoparticles. Kathiresan et al. (Kathiresan et al. 2009) have shown that when the culture filtrate of Penicillium fellutanum was incubated with silver ions and maintained under dark conditions, spherical silver nanoparticles could be produced. They also changed crucial factors such as $\mathrm{pH}$, incubation time, temperature, silver nitrate concentration and sodium chloride to achieve the maximum nanoparticle production. The highest optical density at $430 \mathrm{~nm}$ was found at $24 \mathrm{~h}$ after the start of incubation time, $1 \mathrm{mM}$ concentration of silver nitrate, $\mathrm{pH} 6.0,5^{\circ} \mathrm{C}$ temperature and $0.3 \%$ sodium chloride. Fungi of Penicillium genus were used for green synthesis of silver nanoparticles (Sadowski et al. 
2008). Penicillium sp. J3 isolated from soil was able to produce silver nanoparticles (Maliszewska et al. 2009). The bioreduction of silver ions occurred on the surface of the cells and proteins might have critical role in formation and stabilization of the synthesized nanoparticles.

Sanghi et al. (2009) have investigated the ability of Coriolus versicolor in formation of monodisperse spherical silver nanoparticles. Under alkaline conditions ( $\mathrm{pH} 10)$ the time taken for production of silver nanoparticles was reduced from $72 \mathrm{~h}$ to $1 \mathrm{~h}$. It was indicated that alkaline conditions might be involved in bioreduction of silver ions, water hydrolysis and interaction with protein functionalities. Findings of this study have shown that glucose was necessary for the reduction of silver nanoparticles, and S-H of the protein played an important role in the bioreduction.

\subsubsection{Synthesis of silver nanoparticles by plants}

Camellia sinensis (green tea) extract has been used as a reducing and stabilizing agent for the biosynthesis of silver nanoparticles in an aqueous solution in ambient conditions (VilchisNestor et al. 2008). It was observed that when the amount of C. sinensis extract was increased, the resulted nanoparticles were slightly larger and more spherical. Phenolic acidtype biomolecules (e.g., caffeine and theophylline) present in the C. sinensis extract seemed to be responsible for the formation and stabilization of silver nanoparticles. Black tea leaf extracts were also used in the production of silver nanoparticles (Begum et al. 2009). The nanoparticles were stable and had different shapes, such as spheres, trapezoids, prisms, and rods. Polyphenols and flavonoids seemed to be responsible for the biosynthesis of these nanoparticles.

Plant extracts from alfalfa (Medicago sativa), lemongrass (Cymbopogon flexuosus), and geranium (Pelargonium graveolens) have served as green reactants in silver nanoparticle synthesis. Harris et al. (2008) have investigated the limits (substrate metal concentration and time exposure) of uptake of metallic silver by two common metallophytes, Brassica juncea and $M$. sativa. They demonstrated that B. juncea and $M$. Sativa could be used in the phytosynthesis of silver nanoparticles. B. juncea, when exposed to an aqueous substrate containing 1,000 ppm silver nitrate for $72 \mathrm{~h}$, accumulated up to $12.4 \mathrm{wt}$. \% silver. M. sativa accumulated up to $13.6 \mathrm{wt}$. \% silver when exposed to an aqueous substrate containing $10,000 \mathrm{ppm}$ silver nitrate for $24 \mathrm{~h}$. In the case of $M$. sativa, an increase in metal uptake was observed by increasing the exposure time and substrate concentration. In both cases, TEM analysis showed the presence of roughly spherical silver nanoparticles, with a mean size of $50 \mathrm{~nm}$. Geranium leaf broth, when exposed to aqueous silver nitrate solution, resulted in enzymatic synthesis of stable crystalline silver nanoparticles, extracellularly (Shankar et al. 2003). Bioreduction of the metal ions was fairly rapid, occurred readily in solution, and resulted in a high density of stable silver nanoparticles $(16-40 \mathrm{~nm})$. The nanoparticles appeared to be assembled into open, quasilinear superstructures and were predominantly spherical in shape. It was believed that proteins, terpenoids and other bio-organic compounds in the geranium leaf broth participated in bioreduction of silver ions and in the stabilization of the nanoparticles via surface capping.

A high density of extremely stable silver nanoparticles $(16-40 \mathrm{~nm})$ was rapidly synthesized by challenging silver ions with Datura metel (Solanaceae) leaf extract (Kesharwani et al. 2009). 
The leaf extracts of this plant contains biomolecules, including alkaloids, proteins/enzymes, amino acids, alcoholic compounds, and polysaccharides which could be used as reductant to react with silver ions, and therefore used as scaffolds to direct the formation of silver nanoparticles in the solution. Song and Kim (2008) elucidated the fact that Pinus desiflora, Diospyros kaki, Ginko biloba, Magnolia kobus and Platanus orientalis leaf broths synthesized stable silver nanoparticles with average particle size ranging from 15 to $500 \mathrm{~nm}$, extracellularly. In the case of M. kobus and D. kaki leaf broths, the synthesis rate and final conversion to silver nanoparticles was faster, when the reaction temperature was increased. But the average particle sizes produced by D. kaki leaf broth decreased from $50 \mathrm{~nm}$ to $16 \mathrm{~nm}$, when temperature was increased from $25^{\circ} \mathrm{C}$ to $95^{\circ} \mathrm{C}$. The researchers also illustrated that only $11 \mathrm{~min}$ was required for more than $90 \%$ conversion at the reaction temperature of $95^{\circ} \mathrm{C}$ using M. kobus leaf broth (Song and Kim 2008). It was further demonstrated that leaf extracts from the aquatic medicinal plant, Nelumbo nucifera (Nymphaeaceae), was able to reduce silver ions and produce silver nanoparticles (with an average size of $45 \mathrm{~nm}$ ) in different shapes (Santhoshkumar et al. 2010). The biosynthesized nanoparticles showed larvicidal activities against malaria (Anopheles subpictus) and filariasis (Culex quinquefasciatus) vectors. Silver nanoparticles were biosynthesized using Sorbus aucuparia leaf extract within 15 min. The nanoparticles were found to be stable for more than 3 months. The sorbate ion in the leaf extract of $S$. aucuparia encapsulated the nanoparticles and this action seemed to be responsible for their stability (Dubey et al. 2010).

Studying synthesis of silver nanoparticles with isolated/purified bio-organics may give better insight into the system mechanism. Glutathione ( $\gamma$-Glu-Cys-Gly) as a reducing/capping agent can synthesize water-soluble and size tunable silver nanoparticles which easily bind to a model protein (bovine serum albumin) (Wu et al. 2008). Tryptophan residues of synthetic oligo-peptides at the C-terminus were identified as reducing agents producing silver nanoparticles ( $\mathrm{Si}$ and Mandal 2007). Moreover, silver nanoparticles were synthesized by vitamin $\mathrm{E}$ in Langmuir-Blodgett technique, by bio-surfactants (sophorolipids) and by L-valine-based oligopeptides with chemical structures, Z-(L-Val) $3_{3}-$ OMe and Z-(L-Val) 2-L-Cys (S-Bzl)-OMe (Kasture et al. 2007; Mantion et al. 2008). The sulfur content in the Z-(L-Val) $)_{2}-\mathrm{L}-\mathrm{Cys}(\mathrm{S}-\mathrm{Bzl})-\mathrm{OMe}$ controls the shape and size of silver nanoparticles, which suggests interaction between silver ions and thioether moiety of the peptide (Mantion et al. 2008).

Pure natural constituents could be used to bioreduce and stabilize silver nanoparticles. Kasthuri et al. (Kasthuri et al. 2009) have shown the ability of apiin extracted from henna leaves to produce anisotropic gold and quasi-spherical silver nanoparticles. Secondary hydroxyl and carbonyl groups of apiin were responsible for the bioreduction of metal salts. In order to control size and shape of nanoparticles, they used different amounts of apiin (as the reducing agent). The nanoparticles were stable in water for 3 months, which could be attributed to surface binding of apiin to nanoparticles. Furthermore, geraniol as a volatile compound obtained from $P$. graveolens was used for biosynthesis of silver nanoparticles (1$10 \mathrm{~nm})$. They also evaluated in vitro cytotoxicity of silver nanoparticles against Fibrosarcoma Wehi 164 at different concentrations (1-5 g ml-1) (Safaepour et al. 2009). The presence of 5 $\mathrm{g} / \mathrm{ml}$ of silver nanoparticles significantly inhibited the cell line's growth (up to $60 \%$ ).

The various synthetic and natural polymers such as poly(ethylene glycol), poly-(N-vinyl-2pyrrolidone), starch, heparin, poly-cationic chitosan (1-4-linked 2-amino-2-deoxy- $\beta$-D- 
glucose), sodium alginate, and gum acacia have been reported as reducing and stabilizing agents for biosynthesis of silver nanoparticles. It was reported that monodisperse spherical silver nanoparticles $(3 \mathrm{~nm})$ could be synthesized using gum kondagogu (non-toxic polysaccharide derived as an exudate from the bark of Cochlospermum gossypium) (Kora et al. 2010). It was suggested that carboxylate and hydroxyl groups were involved in complexation and bioreduction of silver ions into nanoparticles. This method was compatible with green chemistry principles as the gum serves a matrix for both bioreduction and stabilization of the synthesized nanoparticles. Due to availability of low cost plant derived biopolymer, this method could be implemented for large-scale synthesis of highly stable monodispersed nanoparticles.

Spherical silver nanoparticles $(40-50 \mathrm{~nm})$ were produced using leaf extract of Euphorbia hirta (Elumalai et al. 2010). These nanoparticles had potential and effective antibacterial property against Bacillus cereus and S. aureus. Acalypha indica (Euphorbiaceae) leaf extracts have produced silver nanoparticles $(20-30 \mathrm{~nm})$ within $30 \mathrm{~min}$ (Krishnaraj et al. 2010). These nanoparticles had excellent antimicrobial activity against water borne pathogens, E. coli and $V$. cholera (Minimum Inhibitory Concentration $(\mathrm{MIC})=10 \mu \mathrm{g} \mathrm{ml}-1$ ). Moreover, silver nanoparticles $(57 \mathrm{~nm}$ ) were produced when $10 \mathrm{ml}$ of Moringa oleifera leaf extract was mixed to $90 \mathrm{ml}$ of $1 \mathrm{mM}$ aqueous of $\mathrm{AgNO}_{3}$ and was heated at $60-80{ }^{\circ} \mathrm{C}$ for $20 \mathrm{~min}$. These nanoparticles had considerable antimicrobial activity against pathogenic microorganisms, including Staphylococcus aureus, Candida tropicalis, Klebsiella pneumoniae, and Candida krusei (Prasad and Elumalai 2011). It has been reported that cotton fibers loaded with biosynthesized silver nanoparticles $(\sim 20 \mathrm{~nm})$ using natural extracts of Eucalyptus citriodora and Ficus bengalensis had excellent antibacterial activity against E. coli. These fibers had potential for utilization in burn/wound dressings as well as in the fabrication of antibacterial textiles and finishings (Ravindra et al. 2010). Garcinia mangostana leaf extract could be used as reducing agent in order to biosynthesize silver nanoparticles $(35 \mathrm{~nm})$. These nanoparticles had high effective antimicrobial activity against E. coli and S. aureus (Veerasamy et al. 2011). It was reported that Ocimum sanctum leaf extract could bioreduce silver ions into crystalline silver nanoparticles $(4-30 \mathrm{~nm})$ within $8 \mathrm{~min}$ of reaction time. These nanoparticles were stable due to the presence of proteins which may act as capping agents. $O$. sanctum leaves contain ascorbic acid which may play an important role in reduction of silver ions into metallic silver nanoparticles. These nanoparticles have shown strong antimicrobial activity against E. coli and S. aureus (Singhal et al. 2011). Green synthesis of silver nanoparticles using Cacumen platycladi extract was also investigated. Reducing sugars and flavonoids in the extract seemed to be mainly responsible for reduction of silver ions, and their reductive capability promoted at $90{ }^{\circ} \mathrm{C}$, leading to formation of silver nanoparticles $(18.4 \pm 4.6 \mathrm{~nm})$ with narrow size distribution. The produced nanoparticles had significant antibacterial activity against both gram negative and gram positive bacteria ( $E$. coli and S. aureus) (Huang et al. 2011). In case of Cinnamon zeylanicum, the bark extract could be used in biosynthesis of cubic and hexagonal silver nanocrystals (31-40 nm) (Sathishkumar et al. 2009). The particle size distribution varied with variation in the amount of $C$. zeylanicum bark extract. The number of particles increased with increasing dosage due to the variation in the amount of reductive biomolecules. Small nanoparticles were formed at high $\mathrm{pH}$. The shape of silver nanoparticles at high $\mathrm{pH}$ was more spherical in nature rather than ellipsoidal. Bactericidal effect of produced nano-crystalline silver particles was tested against E. coli strain. As a result, the various tested concentrations of 2, 5, 10, 25, and $50 \mathrm{mg}$ 
$\mathrm{L}^{-1}$ produced inhibition of $10.9,32.4,55.8,82$, and $98.8 \%$, respectively. The minimum inhibitory concentration was found to be $50 \mathrm{mg} \mathrm{L}^{-1}$.

\section{Applications of silver nanoparticles and their incorporation into other materials}

Nanoparticles are of great interest due to their extremely small size and large surface to volume ratio, which lead to both chemical and physical differences in their properties compared to bulk of the same chemical composition, such as mechanical, biological and sterical properties, catalytic activity, thermal and electrical conductivity, optical absorption and melting point (Daniel and Astruc 2004; Bogunia-Kubik and Sugisaka 2002; Zharov et al. 2005). Therefore, designing and production of materials with novel applications can be resulted by controlling shape and size at nanometer scale. Nanoparticles exhibit size and shape-dependent properties which are of interest for applications ranging from biosensing and catalysts to optics, antimicrobial activity, computer transistors, electrometers, chemical sensors, and wireless electronic logic and memory schemes. These particles also have many applications in different fields such as medical imaging, nano-composites, filters, drug delivery, and hyperthermia of tumors (Tan et al. 2006; Lee et al. 2008; Pissuwan et al. 2006). Silver nanoparticles have drawn the attention of researchers because of their extensive applications in areas such as integrated circuits (Kotthaus et al. 1997), sensors (Cao 2004), biolabelling (Cao 2004), filters (Cao 2004), antimicrobial deodorant fibres (Zhang and Wang 2003), cell electrodes (Klaus-Joerger et al. 2001), low-cost paper batteries (silver nano-wires) (Hu et al. 2009) and antimicrobials (Cho et al. 2005; Dura'n et al. 2007). Silver nanoparticles have been used extensively as antimicrobial agents in health industry, food storage, textile coatings and a number of environmental applications. Antimicrobial properties of silver nanoparticles caused the use of these nanometals in different fields of medicine, various industries, animal husbandry, packaging, accessories, cosmetics, health and military. Silver nanoparticles show potential antimicrobial effects against infectious organisms, including Escherichia coli, Bacillus subtilis, Vibria cholera, Pseudomonas aeruginosa, Syphillis typhus, and S. aureus (Cho et al. 2005; Dura'n et al. 2007). For instance, it was shown that silver nanoparticles mainly in the range of 1-10 $\mathrm{nm}$ attached to the surface of $E$. coli cell membrane, and disturbed its proper function such as respiration and permeability (Morones et al. 2005). It was observed that silver nanoparticles had a higher antibacterial effect on $B$. subtilis than on E. coli, suggesting a selective antimicrobial effect, possibly related to the structure of the bacterial membrane (Yoon et al. 2007). As antimicrobial agents, silver nanoparticles were applied in a wide range of applications from disinfecting medical devices and home appliances to water treatment (Jain and Pradeep 2005; Li et al. 2008). The synergetic activities of silver nanoparticles and antibiotics such as erythromycin, amoxicillin, penicillin G, clindamycin, and vancomycine against E. coli and S. aureus was reported (Shahverdi et al. 2007). Silver nanoparticles were also used in medical devices (e.g., polymethylmetacrylate bone cement, surgical masks and implantable devices) to increase their antimicrobial activities (Figure 2). For instance, plastic catheters which were coated with silver nanoparticles using silver nitrate $\left(\mathrm{AgNO}_{3}\right)$, surfactant and $N, N, N$ ',N 'tetramethylethylenediamine (as a reducing agent), had significant antimicrobial effects against E. coli, Enterococcus, S. aureus, C. albicans, Staphylococci, and P. aeroginosa (Roe et al. 2008). These can be useful for reducing the risk of infectious complications in patients with indwelling catheters. Silver nanoparticles/clay was reported to have significant 
antimicrobial effects against dermal pathogens, including S. aureus, P. aeruginosa, and Streptococcus pyrogens, as well as the methicillin- and oxacillin resistant S. aureus (MRSA and ORSA) (Su et al. 2009).

Antifungal effects of silver nanoparticles against fungal pathogens are mostly unknown. However, it was reported that these nanoparticles had significant antifungal activities against T. mentagrophytes and Candida species (such as C. albicans, C. tropicolis, C. glabrata, C. parapsilosis, and C. krusei). Silver nanoparticles disrupt fungal envelope structure and lead to significant damage to fungal cells (Kim et al. 2008; Kim et al. 2009).

Sun et al demonstrated the cytoprotective activity of silver nanoparticles (5-20 nm) toward HIV-1 infected cells (Hut/CCR5). These nanoparticles inhibited the virus replication in Hut/CCR5 cells causing HIV-associated apoptosis (Sun et al. 2005). In addition, sizedependent antiviral activities of silver nanoparticles (exclusively within the range of 1-10 $\mathrm{nm}$ ) against HIV-1 virus have been reported. Silver nanoparticles preferentially bind to the gp120 subunit of HIV-1 viral envelope glycoprotein, and this interaction caused the virus could not bind to the host cell (Elechiguerra et al. 2005). It seems that more investigations are needed to find the mechanisms of antiviral effects of silver nanoparticles.

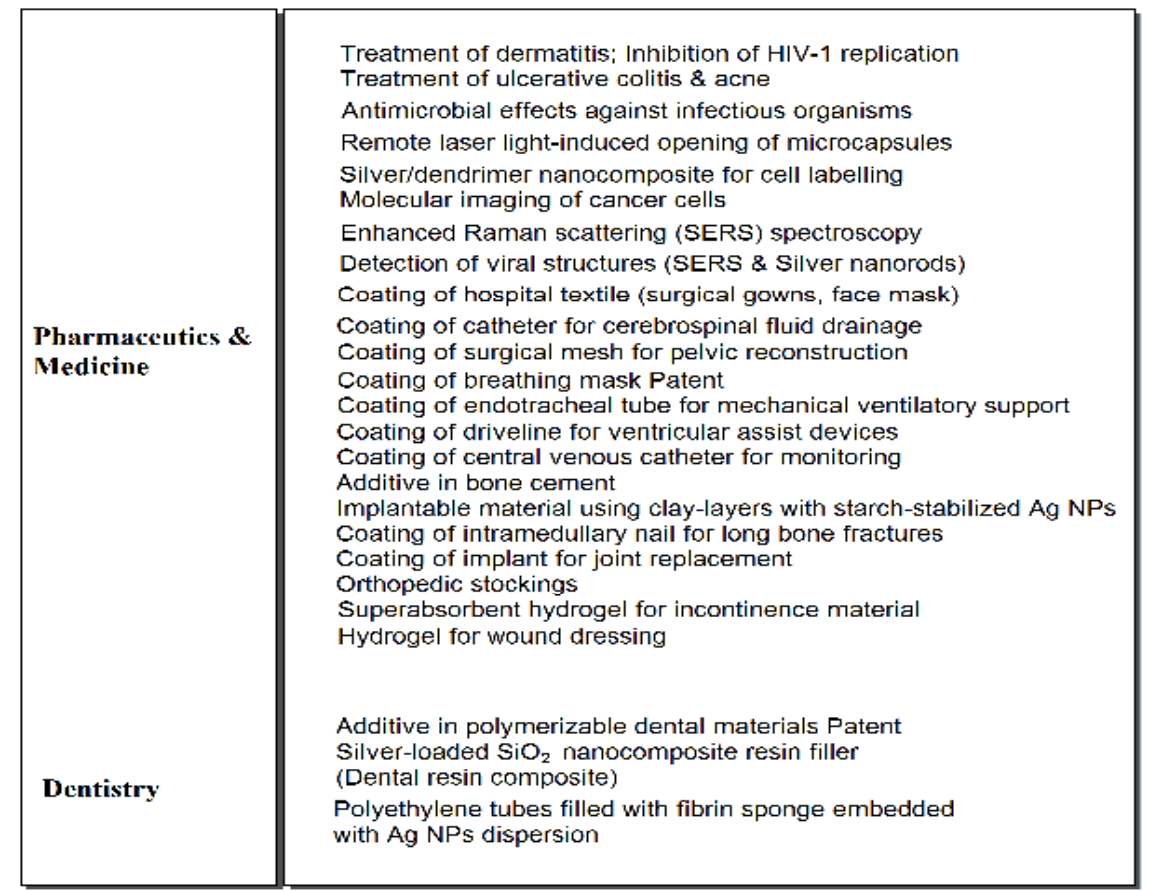

Fig. 2. Applications of silver nanoparticles in pharmaceutics, medicine, and dentistry

In general, therapeutic effects of silver particles (in suspension form) depend on important aspects, including particle size (surface area and energy), particle shape (catalytic activity), particle concentration (therapeutic index) and particle charge (oligodynamic quality) (Pal et al. 2007). Mechanisms of antimicrobial effects of silver nanoparticles are still not fully 
understood, but several studies have revealed that silver nanoparticles may attach to the negatively charged bacterial cell wall and rupture it, which leads to denaturation of protein and finally cell death (Figure 3). Fluorescent bacteria were used to study antibacterial effects of silver nanoparticles. Green fluorescent proteins were adapted to these investigations (Gogoi et al. 2006). It was found that silver nanoparticles attached to sulfur-containing proteins of bacteria, and caused death. Moreover, fluorescent measurements of cell-free supernatants showed the effect of silver nanoparticles on recombination of bacteria. The attachment of silver ions or nanoparticles to the cell wall caused accumulation of envelope protein precursors resulting in immediate dissipation of the proton motive force (Lin et al. 1998). Catalytic mechanism of silver nanoparticle composites and their damage to the cell by interaction with phosphorous- and sulfur-containing compounds such as DNA have been also investigated (Sharma et al. 2009). Furthermore, silver nanoparticles exhibited destabilization of the outer membrane and rupture of the plasma membrane, thereby causing depletion of intracellular ATP (Lok 2006). Another mechanism involves the association of silver with oxygen and its reaction with sulfhydryl groups on the cell wall to form R-S-S-R bonds, thereby blocking respiration and causing cell death (Kumar et al. 2004).

\begin{tabular}{|c|}
\hline Mechanisms of Antibacterial ElTects ol' $A_{y}$ Nanoparticles \\
\hline Cell death due to uncoupling of oxidative phosphorylation \\
\hline Cell death due to induction of free radical formation \\
\hline Interference with respiratory chain at cytochrome C level \\
\hline Interference with components of microbial electron transport system \\
\hline Interactions with protein thiol groups \& membrane bound enzymes \\
\hline Interaction with phosphorous- and sulfur-containing compounds \\
such as DNA
\end{tabular}

Fig. 3. Mechanisms of antibacterial effects of silver nanoparticles

Products made with silver nanoparticles have been approved by a range of accredited bodies such as US Food and Drug Administration (FDA), US Environmental Protection Agency (EPA), and Research Institute for Chemical Industry and FITI Testing (Zhong et al. 2007; Wei et al. 2007; Jia et al. 2008). Silver nanoparticles can be exploited in medicine and pharmacy for dental materials, burn treatments, coating stainless steel materials, textile fabrics, and sunscreen lotions (Duran et al. 2007). Silver nanoparticles are widely used in surface enhanced Raman scattering (SERS) spectroscopy (surface-sensitive technique which is known for its high sensitivity due to its surface plasmon effects lacks behind at uniform substrate formation) because of high local field enhancement factor. For example, it was 
demonstrated that SERS and silver nanorods quickly revealed the viral structures (Shanmukh et al. 2006). It can also differentiate between respiratory viruses, virus strains, and viruses containing gene deletions without manipulating the virus. Silver nanoparticles can also be used for modification of polymer based diffraction gratings which further can be used in grating light reflection spectroscopy for sensing (Šileikaitė et al. 2007; Abu Hatab et al. 2008). Furthermore, the electrochemical properties of silver nanoparticles incorporated them in nano-scale sensors which can offer faster response times and lower detection limits (Manno et al. 2008; Hahm and Lieber 2004). Manno et al. (Hahm and Lieber 2004) electrodeposited silver nanoparticles onto alumina plates gold micro-patterned electrode which showed a high sensitivity to hydrogen peroxide $\left(\mathrm{H}_{2} \mathrm{O}_{2}\right)$. Silver nanoparticles were found to catalyze the chemiluminescence from luminal-hydrogen peroxide system with catalytic activity better than $\mathrm{Au}$ and Pt colloid (Guo et al. 2008). The catalytic properties of silver nanoparticles varied from their size and morphology. It was reported that when the silver colloid was injected, chemiluminoscence emission from the luminal- $\mathrm{H}_{2} \mathrm{O}_{2}$ system was greatly enhanced (Guo et al. 2008). Silver nanoparticles supported halloysite nanotubes (Ag/HNTs), with silver content of approximately $11 \%$, was applied to catalyze reduction of 4-nitrophenol with $\mathrm{NaBH}_{4}$ in alkaline aqueous solutions (Liu and Zhao 2009). Nano-clusters composed of 2-8 silver atoms could be the basis for a new type of optical data storage. Moreover, fluorescent emissions from the clusters could also potentially be used in biological labels and electroluminescent displays (Berciaud et al. 2005; Kossyrev et al. 2005). The optical properties of a metallic nanoparticle depend mainly on its surface plasmon resonance, where the plasmon refers to the collective oscillation of the free electrons within the metallic nanoparticle. The plasmon resonant peaks and line widths are sensitive to the size and shape of the nanoparticle, the metallic species and the surrounding medium. The optical properties of silver nanoparticles have been taken advantage of optical chemosensors and biosensors. For instance, triangular silver nanoparticles have been used in measurement of biological binding signal between antibodies and antigens (Zhu et al. 2009).

Metal nanoparticles embedded into polymer matrix can be used as sensors, materials with solvent switchable electronic properties, optical limiters and filters, and optical data storage. They can be applied for catalytic applications and antimicrobial coatings. Production of metal/polymer nanocomposites in poly(methyl methacrylate), $\mathrm{N}$-isopropylacrylamide, diallyldimethylammonium chloride, poly(vinyl alcohol), poly(vinyl acetate), poly(vinyl carbazole), and polyimide films has been reported (Boyd et al. 2006; Sakamoto et al. 2007; Sakamoto et al. 2009). Nanocomposites of polymer/silver nanoparticles have attracted great attention because of their potential applications in the fields of catalysis, bioengineering, photonics, and electronics (Kiesow et al. 2003). Polymers are considered good host materials for metallic nanoparticles as well as other stabilizing agents, including citrates, organic solvents (e.g., tetrahydrofuran and tetrahydrofuran/methanol), long chain alcohols, surfactants, and organometallics (Sarkar et al. 2005; Chen et al. 2001). Various chemical and physical methods were applied to prepare metal-polymer composites (e.g., fabrication approach) (Kiesow et al. 2003; Rifai et al. 2006). Fabrication approach is often referred to as the evaporation method since the polymer solvent is evaporated from the reaction mixture after nanoparticle dispersion. However, this often leads to inhomogeneous distribution of the particles in the polymer. A successful production of nanoparticles is determined by the ability to produce particles with uniform distributions and long stability, given their 
tendency to rapidly agglomerate in aqueous solution (Rifai et al. 2006). Another approach is a system in which simultaneous polymerization and metal reduction occur. For instance, polychrome silver nanoparticles were obtained by microwave irradiation from a solution of silver nitrate in the presence of poly( $\mathrm{N}$-vinyl-2-pyrrolidone) without any other reducing agent. The in-situ reduction of silver ions in poly(N-vinyl-2-pyrrolidone) by microwave irradiation produced particles with narrow size distribution (He et al. 2002; Mohan et al. 2007). Moreover, silver nanoparticles (approximately $5 \mathrm{~nm}$ ) were prepared by mixing equal amounts of $0.5 \mathrm{wt} \%$ aqueous solutions of acacia (natural polymer) and silver nitrate. In this process, acacia polymeric chains promote the reduction and act as good stabilizers over 5 months (He et al. 2002; Mohan et al. 2007).

Conventional heating approach (simultaneous polymerization-reduction method) to polymerize acrylonitrile reduces silver ions resulting in homogeneous dispersal and narrow size distributions of the silver nanoparticles in silver-polyacrylonitrile composite powders (Zhang and Han 2003). Moreover, size-controlled synthesis of silver nano-complex was recently achieved in reduction of silver nitrate by a UV-irradiated argine-tungstonsilicate acid solution (Yang et al. 2007). Other various metal-polymer nano-composites have been prepared by these reduction methods, such as poly(vinyl alcohol)-Ag, Ag-polyacrylamide, Ag-acrylonitrile, $\mathrm{Ag}_{2}$ Se-polyvinyl alcohol, Ag-polyimide, Au-polyaniline, and Cupoly(acrylic acid) (Ma et al. 2002; Akamatsu et al. 2003). Poly(vinyl alcohol) (a water soluble and biocompatible polymer with extremely low cytotoxicity) has a lot of biomedical applications. This biologically friendly polymer can be used as a stabilizer due to its optical clarity and classified into grades of partially (85-89\%) and fully (97-99.5\%) hydrolyzed polymers (Badr and Mahmoud 2006). This polymer was widely used in textile, paper industries, food packaging, pharmacy, and cosmetics. Introduction of nano-sized silver into poly(vinyl alcohol) provides antibacterial activity, which is highly desired in textiles used in medicine, wound dressing applications, clothing and household products (Hong et al. 2006). For instance, poly(vinyl alcohol) nanofibers containing silver nanoparticles were prepared by electro-spinning poly(vinyl alcohol)/silver nitrate aqueous solutions, followed by short heat treatment. The produced nanofibers containing silver nanoparticles showed strong antimicrobial activities (Hong et al. 2006). Various approaches such as solvent evaporation, electron and ultraviolet radiation, in situ chemical reduction, thermal annealing, and sonochemical method have been applied to synthesize poly(vinyl alcohol)-silver nanoparticles (Sharma et al. 2009). In solvent evaporation methods, synthesis of poly(vinyl alcohol)-silver nanoparticles was achieved by first reducing silver salt with $\mathrm{NaBH}_{4}$, followed by mechanical dispersion of the silver colloids into the dissolved polymer, and then the solvent was evaporated resulting in final structure. Electron and ultraviolet radiation approaches involve irradiation of $\mathrm{a} \mathrm{Ag}^{+}$doped polymer film which gives poly(vinyl alcohol)-silver nano-composites (Sharma et al. 2009). In one study, silver nanoparticles have been prepared in poly(vinyl alcohol) matrix by thermal treatments. The annealing time and temperature vary morphologies of poly(vinyl alcohol)-silver nanoparticles (Clemenson et al. 2007). Moreover, hydrogels of poly(vinyl alcohol)- poly(N-vinyl pyrolidone containing silver nanoparticles were produced by repeated freezing-thawing treatments. These nanosilvercontaining hydrogels had excellent antibacterial effects against $E$. coli and S. aureus (Yu et al. 2007). 
Apatite-coated $\mathrm{Ag} / \mathrm{AgBr} /$ titanium dioxide $\left(\mathrm{TiO}_{2}\right)$ was prepared by deposition of silver to generate electron-hole pairs by extending the excitation wavelength to the visible-light region, $\mathrm{AgBr}$, and hydroxy apatite as photosensitive material and adsorption bioceramic, respectively (Elahifard et al. 2007). In another study, nanoparticle photocatalysts based on silver, carbon, and sulfur-doped titanium dioxide were synthesized by a modified sol-gel method (Hamal and Klabunde 2007). Silver/ $\mathrm{TiO}_{2}$ nano-composites and poly(vinyl alcohol)capped colloidal silver- $\mathrm{TiO}_{2}$ nano-composites were prepared. The synthesized nanocomposites were effective toward destroying Gram-negative bacteria, e.g. Escherichia coli. (Guin et al. 2007). These silver $/ \mathrm{TiO}_{2}$ surfaces had advantageous properties, including visible light photocatalysis, biological compatibility, and antimicrobial activities (Elahifard et al. 2007; Seery et al. 2007; Hamal and Klabunde 2007). For example, $\mathrm{Ag} / \mathrm{TiO}_{2}$ composite films were prepared by incorporating silver in the pores of titanium dioxide films with an impregnation method via photoreduction (a versatile and convenient process with advantage of space-selective fabrication). It was reported that these composite films are promising in application of photocatalysis, antimicrobial and self-clean technologies (Liu et al. 2008). In order to synthesize silver nanoparticles on titanium dioxide surfaces, aqueous reduction, photochemical (in-situ photochemical fabrication approach can be used for preparation of metal nanoparticles/polymer nano-composites), liquid phase deposition, and sol-gel methods can be applied (Zheng et al. 2008; Elahifard et al. 2007; Seery et al. 2007; Liu et al. 2008; Hamal and Klabunde 2007; Cozzoli et al. 2004). Silver nanoparticles with a narrow size distribution were prepared by simple aqueous reduction from silver ions in different molar ratios of titanium dioxide suspensions and $\mathrm{NaBH}_{4}$ (reducing agent) (NinoMartinez et al. 2008). One of the photochemical reduction methods involves loading silver nanoparticles (3-5 nm) onto the surface of titanium dioxide nano-tubes first using the liquid deposition approach followed by UV or laser irradiation (Li et al. 2008).

\section{Toxicity of nano-silver particles}

Nano-sized particles can pass through biological membranes and penetrate even very small capillaries throughout the body (e.g., pass through blood-brain and blood testes barriers). Size, morphology, and surface area are recognized as important determinants for toxicity of nanoparticles (Ji et al. 2007). Information on the toxicological implication of silver nanoparticles is limited (Chen and Schluesener 2008). Toxicity of silver nanoparticles is mostly determined in vitro with particles ranging from approximately $1-100 \mathrm{~nm}$. The in vitro and in vivo toxicity studies revealed that silver nanoparticles have the potential ability to cause chromosomal aberrations and DNA damage, to enter cells and cause cellular damage, and are capable of inducing proliferation arrest in cell lines of zebra fish (Ji et al. 2007; Asharani PV et al. 2007; Hussain SM et al. 2005). Limited health effects of the use of nanosilver particles in humans have been reported, such as argyria (a condition in which the skin becomes blue or bluish-grey colored because of improper exposure to chemical forms of element) which was appeared to occur only after intake of large amounts of colloidal silver particles (the suspension with nano-silver of different sizes). Several cross-sectional studies reported that argyria is the most frequent adverse outcome from exposure to silver nanoparticles. For instance, prolonged ingestion of colloidal silver can change the color of skin and cause blue-grey appearance on face (the symptoms of argyria) (Chang et al. 2006). Silver nanoparticles can bind to different tissues (bind to proteins and enzymes in mammalian cells) and cause toxic effects, such as adhesive interactions with cellular 
membrane and production of highly reactive and toxic radicals like reactive oxygen species (ROS), which can cause inflammation and show intensive toxic effects on mitochondrial function. Potential target organs for nano-silver toxicity may involve liver and immune system. Accumulation and histopathological effects were seen in livers from rats systemically exposed to silver nanoparticles $(10-15 \mathrm{~nm})$. Furthermore, increased liver enzymes were reported in Sprague-Dawley rats after Twenty-eight-day oral exposure to nano-silver particles $(60 \mathrm{~nm})$ (Kim et al. 2008). It was reported that silver-coated dressing acticoat caused raised liver enzymes and argyria-like symptoms in burn patients (Trop et al. 2006). The in vitro and in vivo studies revealed toxicity effects of silver nanoparticles on immune system, especially cytokine excretion. Application of 1\% nano-silver cream (silver nanoparticles with size range of approximately $50 \mathrm{~nm}$ ), inhibited DNB-induced allergic contact dermatitis, and accumulation in the spleen has also been reported (Bhol and Schechter 2007; Takenaka et al. 2001). It has been suggested that silver nanoparticles are especially effective at inhibiting inflammations and may be used to treat immunologic and inflammatory diseases (Shin et al. 2007). Oral administration of silver nanoparticles $(60 \mathrm{~nm})$ to rats induced some local inflammatory effects (Kim et al. 2008). Moreover, in one in vitro study, toxicity effects of nano-silver particles on erythrocytes was reported (Garner et al. 1994), while an increase in red blood cells was seen after oral administration of silver nanoparticles $(60 \mathrm{~nm})$ (Kim et al. 2008), but not after inhalation of silver nanoparticles (15 $\mathrm{nm}$ ) (Ji et al. 2007). An in vitro study suggests that nano-silver particles may have cytotoxic effects on mammalian (mouse) spermatogonial germ line stem cells (Braydich-Stolle et al. 2005). Silver nanoparticles ( $10 \mu \mathrm{g} \mathrm{ml}^{-1}$ and above concentration) showed dramatic changes such as necrosis and apoptosis of the cells and at 5-10 $\mu \mathrm{g} \mathrm{ml}^{-1}$ drastically reduced mitochondrial function and cell viability. It was reported that there is no evidence available to demonstrate that silver is a cause of neurotoxic damage even though silver deposits have been identified in the region of cutaneous nerves (Lansdown 2007). The respiratory system seemed relatively unaffected by exposure to nano-silver in vivo in a 28 days study (Ji et al. 2007). However, cytotoxic effect of nano-silver particles on alveolar macrophages and alveolar epithelial cells was demonstrated, in vitro (Soto et al. 2005; Soto et al. 2007; Park et al. 2007). In a 90 days inhalation study, decrease in lung functions, including tidal volume, minute volume and peak inspiration flow as well as inflammatory lesions in lung morphology and effects on inflammatory markers were reported (Sung et al. 2008). Kim et al. (2008) performed a bone marrow micronucleus test as a part of a 28-day oral administration study in order to investigate genotoxic effects or carcinogenicity of exposure to silver nanoparticles. No significant genotoxic potential of oral exposure to silver nanoparticles $(60 \mathrm{~nm})$ was found in this study. An increase in (mostly local) malignant tumors was found following chronic subcutaneous administration of high doses colloidal silver (Schmaehl and Steinhoff 1960).

\section{Conclusion}

Silver nanoparticles have attracted the attention of researchers because of their unique properties, and proven applicability in diverse areas such as medicine, catalysis, textile engineering, biotechnology, nanobiotechnology, bioengineering sciences, electronics, optics, and water treatment. Moreover, silver nanoparticles have significant inhibitory effects against microbial pathogens, and are widely used as antimicrobial agents in a diverse range of consumer products, including air sanitizer sprays, socks, pillows, slippers, respirators, 
wet wipes, cosmetics, detergents, soaps, shampoos, toothpastes, air and water filters, coatings of refrigerators, vacuum cleaners, bone cement, wound dressings, surgical dressings, washing machines, food storage packaging, and cell phones. The flexibility of silver nanoparticle synthetic methods and facile incorporation of silver nanoparticles into different media have interested researchers to further investigate the mechanistic aspects of antimicrobial, antiviral and anti-inflammatory effects of these nanoparticles.

In brief, there are limited well-controlled investigations on potential toxicities of nano-silver particles, and it seems that additional long-term studies (preferably using multiple particle sizes) are needed to better characterize and understand the risk of using these particles.

Various chemical, physical and biological synthetic methods have been developed to obtain silver nanoparticles of various shapes and sizes, including laser ablation, gamma irradiation, electron irradiation, chemical reduction, photochemical methods, microwave processing, and thermal decomposition of silver oxalate in water and in ethylene glycol, and biological synthetic methods. Most of these methods are still in the development stages and the problems experienced involve the stability and aggregation of nanoparticles, control of crystal growth, morphology, size and size distribution, and occasional difficulty in the management of the synthesis, as in the case of the radiolysis technique. Moreover, the separation of produced nanoparticles for further applications is still an important issue. By using different reducing agents and stabilizers, the particle size and morphology of silver nanoparticles have been controlled. Selection of solvent medium and selection of ecofriendly nontoxic reducing and stabilizing agents are the most important issues which must be considered in green synthesis of silver nanoparticles. In biological synthetic methods, it was shown that the silver nanoparticles produced by plants are more stable in comparison with those produced by other organisms. Plants (especially plant extracts) are able to reduce silver ions faster than fungi or bacteria. Furthermore, in order to use easy and safe green methods in scale-up and industrial production of well-dispersed silver nanoparticles, plant extracts are certainly better than plant biomass or living plants. However, better experimental procedures are needed for synthesis of well-characterized nanoparticles.

\section{Acknowledgment}

The authors appreciate the support of Isfahan University of Medical Sciences.

\section{References}

Abid, J.P.; Wark, A.W.; Brevet, P.F. \& Girault H.H. (2002). Preparation of silver nanoparticles in solution from a silver salt by laser irradiation. Chem Commun, 792-793

Abu Hatab, N.A.; Oran, J.M. \& Sepaniak, M.J. (2008). Surface-enhanced raman spectroscopy substrates created via electron beam lithography and nanotransfer printing. American Chemical Society ACS NANO, Vol.2, pp.377-385

Ahmad, A.; Mukherjee, P.; Senapati, S.; Mandal, D.; Khan, M.I.; Kumar, R. \& Sastry, M. (2003a). Extracellular biosynthesis of silver nanoparticles using the fungus Fusarium oxysporum, Colloids and Surfaces B: Biointerfaces, Vol.28, pp.313-318

Ahmad, A.; Senapati, S.; Khan, M.I.; Kumar, R.; Ramani, R.; Srinivas, V. \& Sastry, M.(2003b). Intracellular synthesis of gold nanoparticles by a novel alkalotolerant actinomycete, Rhodococcus species. Nanotechnology, Vol.14, pp.824-828 
Akamatsu, K.; Ikeda, S. \& Nawafune, H. (2003). Site-selective direct silver metallization on surface-modified polyimide layers. Langmuir, Vol.19, pp.10366-10371

Ankamwar, B.; Damle, C.; Ahmad, A. \& Sastry, M. (2005). Biosynthesis of gold and silver nanoparticles using Emblica officinalis fruit extract, their phase transfer and transmetallation in an organic solution. J Nanosci Nanotechnol, Vol.5, pp.1665-1671

Asharani, P.V.; Nair, G.; Zhiyuan, H.; Manoor, P. \& Valiyaveettil, S. (2007). Potential health impacts of silver nanoparticles. Abstracts of Papers, 234th ACS National Meeting, Boston, MA, USA, August:19-23, 2007. pp:TOXI-2099.

Badr, Y. \& Mahmoud, M.A. (2006). Enhancement of the optical properties of poly vinyl alcohol by doping with silver nanoparticles. J Appl Polym Sci, Vol.99, pp.3608-3614

Balaji, D.S.; Basavaraja, S.; Deshpande, R.; Bedre Mahesh, D.; Prabhakar, B.K. \& Venkataraman, A. (2009). Extracellular biosynthesis of functionalized silver nanoparticles by strains of Cladosporium cladosporioides fungus. Colloids and Surfaces B: Biointerfaces, Vol.68, pp.88-92

Begum, N.A.; Mondal, S.; Basu, S.; Laskar, R.A. \& Mandal, D. (2009). Biogenic synthesis of $\mathrm{Au}$ and $\mathrm{Ag}$ nanoparticles using aqueous solutions of Black Tea leaf extracts. Colloids and Surfaces B: Biointerfaces, Vol.71, pp.113-118

Berciaud, S.; Cognet, L.; Tamarat, P. \& Lounis, B. (2005). Observation of intrinsic size effects in the optical response of individual gold nanoparticles. Nano Lett, Vol.5,pp.515518

Bhainsa, K.C. \& D'Souza, S. (2006). Extracellular biosynthesis of silver nanoparticles using the fungus Aspergillus fumigatus. Colloids and Surfaces B: Biointerfaces, Vol.47, pp.160164

Bhol, K.C. \& Schechter, P.J. (2007). Effects of nanocrystalline silver (NPI 32101) in a rat model of ulcerative colitis. Digestive Dis Sci, Vol.52, pp.2732-2742

Bogle, K.A.; Dhole, S.D. \& Bhoraskar, V.N. (2006). Silver nanoparticles: synthesis and size control by electron irradiation. Nanotechnology, Vol.17, pp.3204

Bogunia-Kubik, K. \& Sugisaka, M. (2002). From molecular biology to nanotechnology and nanomedicine. Biosystems, Vol.65, pp.123-138

Boyd, D.A.; Greengard, L.; Brongersma, M.; El-Naggar, M.Y. \& Goodwin, D. (2006). Plasmon-assisted chemical vapor deposition. Nano Lett, Vol.6, pp.2592-2597

Braydich-Stolle, L.; Hussain, S.; Schlager, J.J. \& Hofmann, M.C. (2005). In vitro cytotoxicity of nanoparticles in mammalian germline stem cells. Toxicol Sci, Vol.88, pp.412-419

Brust, M. \& Kiely, C. (2002). Some recent advances in nanostructure preparation from gold and silver particles: a short topical review. Colloids Surf A: Phys Eng Aspects, Vol.202, pp.175-186

Cao, G. (2004). Nanostructures and nanomaterials: synthesis, properties and applications. Imperial College Press, ISBN: 1-86094-4159, London

Chang, A.L.S.; Khosravi, V. \& Egbert, B. (2006). A case of argyria after colloidal silver ingestion. J Cutan Pathol, Vol.33, pp.809-811

Chen, J.; Wang, K.; Xin, J. \& Jin, Y. (2008). Microwave-assisted green synthesis of silver nanoparticles by carboxymethyl cellulose sodium and silver nitrate. Mater Chem Phys, Vol.108, pp.421-424

Chen, W.; Cai, W.; Zhang, L.; Wang, G. \& Zhang, L. (2001). Sonochemical Processes and Formation of Gold Nanoparticles within Pores of Mesoporous Silica. J Colloid Interface Sci, Vol.238, pp.291-295 
Chen, X. \& Schluesener, H.J. (2008). Nano-silver: A nanoproduct in medical application. Toxicol Lett, Vol.176, pp.1-12

Cheng, P.; Song, L.; Liu, Y. \& Fang, Y.E. (2007). Synthesis of silver nanoparticles by Y-ray irradiation in acetic water solution containing chitosan. Radiat Phys Chem, Vol.76, pp.1165-1168

Cho, K-H.; Park, J-E.; Osaka, T. \& Park, S.G. (2005). The study of antimicrobial activity and preservative effects of nanosilver ingredient. Electrochimica Acta, Vol.51, pp.956-960

Clemenson, S.; David, L. \& Espuche, E. (2007). Structure and morphology of nanocomposite films prepared from polyvinyl alcohol and silver nitrate: Influence of thermal treatment. J Polym Sci Part A Polym Chem, Vol.45, pp.2657-2672

Colvin, V.L.; Schlamp, M.C. \& Alivisatos, A. (1994). Light emitting diodes made from cadmium selenide nanocrystals and a semiconducting polymer. Nature, Vol.370, pp.354-357

Cozzoli, P.; Comparelli, R.; Fanizza, E.; Curri, M.; Agostiano, A. \& Laub, D. (2004). Photocatalytic synthesis of silver nanoparticles stabilized by $\mathrm{TiO}_{2}$ nanorods: a semiconductor/metal nanocomposite in homogeneous nonpolar solution. J Am Chem Soc, Vol.126, pp.3868-3879

Daniel, M.C. \& Astruc, D. (2004). Gold nanoparticles: assembly, supramolecular chemistry, quantum-size-related properties, and applications toward biology, catalysis, and nanotechnology. Chem Rev, Vol.104, pp.293-346

Dolgaev, S.I.; Simakin, A.V.; Voronov, V.V.; Shafeev, G.A. \& Bozon-Verduraz, F. (2002). Nanoparticles produced by laser ablation of solids in liquid environment. Appl Surf Sci, Vol.186, pp.546-551

Dubey, S.P.; Lahtinen, M.; Särkkä, H. \& Sillanpää, M. (2010). Bioprospective of Sorbus aucuparia leaf extract in development of silver and gold nanocolloids. Colloids and Surfaces B: Biointerfaces, Vol.80, pp.26-33

Dura'n, N.; Marcato, P.D.; De, S.; Gabriel, I.H.; Alves, O.L. \& Esposito, E. (2007). Antibacterial effect of silver nanoparticles produced by fungal process on textile fabrics and their effluent treatment. J Biomed Nanotechnol, Vol.3, pp.203-208

Duran, N.; Marcato, D.P.; De Souza, H.I.; Alves, L.O. \& Espsito, E. (2007). Antibacterial effect of silver nanoparticles produced by fungal process on textile fabrics and their effluent treatment. J Biomedical Nanotechnology, Vol.3, pp.203-208

Elahifard, M.R.; Rahimnejad, S.; Haghighi, S. \& Gholami, M.R. (2007). Apatite-coated $\mathrm{Ag} / \mathrm{AgBr} / \mathrm{TiO}_{2}$ visible-light photocatalyst for destruction of bacteria. J Am Chem Soc, Vol.129, pp.9552-9553

Elechiguerra, J.L.; Burt, J.L.; Morones, J.R.; Camacho-Bragado, A.; Gao, X.; Lara, H.H. \& Yacaman, M.J. (2005). Interaction of silver nanoparticles with HIV-1. J Nanobiotechnol, Vol.3:6

Elumalai, E.K.; Prasad, T.N.V.K.V.; Hemachandran, J.; Viviyan Therasa, S.; Thirumalai, T. \& David, E. (2010). Extracellular synthesis of silver nanoparticles using leaves of Euphorbia hirta and their antibacterial activities. J Pharm Sci \& Res, Vol.2, pp.549-554

Eutis, S.; Krylova, G.; Eremenko, A.; Smirnova, N.; Schill, A.W. \& El-Sayed, M. (2005). Growth and fragmentation of silver nanoparticles in their synthesis with a fs laser and CW light by photo-sensitization with benzophenone. Photochem Photobiol Sci, Vol.4, pp.154-159 
Evanoff, Jr. \& Chumanov, G. (2004). Size-controlled synthesis of nanoparticles. 2. measurement of extinction, scattering, and absorption cross sections. J Phys Chem B, Vol.108, pp.13957-13962

Garner, M.; Reglinski, J.; Smith, W.E. \& Stewart, M.J. (1994). The interaction of colloidal metals with erythrocytes. J Inorg Biochem, Vol.56, pp.283-290

Gogoi, K.S.; Gopina, P.; Paul, A.; Ramesh, A.; Ghosh, S.S. \& Chattopadhyay, A. (2006). Green fluorescent protein expressing Escherichia coli as a model system for investigating the antimicrobial activities of silver nanoparticles. Langmuir, Vol.22, pp.9322-9328

Guin, D.; Manorama, S.V.; Latha, J.N.L. \& Singh, S. (2007). Photoreduction of silver on bare and colloidal $\mathrm{TiO}_{2}$ nanoparticles/nanotubes: synthesis, characterization, and tested for antibacterial outcome. J Phys Chem C, Vol.111, pp.13393-13397

Guo, J-Z.; Cui, H.; Zhou, W. \& Wang, W. (2008). Ag nanoparticle-catalyzed chemiluminescent reaction between luminal and hydrogen peroxide. J Photochem Photobiol A: Chem, Vol.193, pp.89-96

Guo, J.; Cui, H.; Zhou, W. \& Wang, W. (2008). Ag nanoparticle-catalyzed chemiluminescent reaction between luminol and hydrogen peroxide. J Photochem Photobiol A: Chem, Vol.193, pp.89-96

Hahm, J. \& Lieber, C. (2004). Direct ultrasensitive electrical detection of DNA and DNA sequence variations using nanowire nanosensors. Nano Lett, Vol.4, pp.51-54

Hamal, D.B. \& Klabunde, K.J. (2007). Synthesis, characterization, and visible light activity of new nanoparticle photocatalysts based on silver, carbon, and sulfur-doped $\mathrm{TiO}_{2}$. J Colloid Interface Sci, Vol.311, pp.514-522

Hamilton, J.F. \& Baetzold, R. (1979). Catalysis by small metal clusters. Science, Vol.205, pp.1213-1220

Harris, A.T. \& Bali, R. (2008). On the formation and extent of uptake of silver nanoparticles by live plants. J Nanopart Res, Vol.10, pp.691-695

He, R.; Qian, X.; Yin, J. \& Zhu, Z. (2002). Preparation of polychrome silver nanoparticles in different solvents. J Mater Chem, Vol.12, pp.3783-3786

Hoffman, A.J.; Mills, G.; Yee, H. \& Hoffmann, M. (1992). Q-sized cadmium sulfide: synthesis, characterization, and efficiency of photoinitiation of polymerization of several vinylic monomers. J Phys Chem, Vol.96, pp.5546-5552

Hong, K.H.; Park, J.L.; Sul, I.H.; Youk, J.H. \& Kang, T.J. (2006). Preparation of antimicrobial poly(vinyl alcohol) nanofibers containing silver nanoparticles. J Polym Sci Part B Polym Phys, Vol.44, pp.2468-2474

Hornebecq, V.; Antonietti, M.; Cardinal, T. \& Treguer-Delapierre, M. (2003). Stable silver nanoparticles immobilized in mesoporous silica. Chemistry of Materials, Vol.15, pp.1993-1999

Hu, B.; Wang, S-B.; Wang, K.; Zhang, M. \& Yu, S.H. (2008). Microwave-assisted rapid facile "green" synthesis of uniform silver nanoparticles: Self-assembly into multilayered films and their optical properties. J Phys Chem C, Vol.112, pp.11169-11174

Hu, L.; Choi, J.W.; Yang, Y.; Jeong, S.; La Mantia, F.; Cui, L-F. \& Cui, Y. (2009). Highly conductive paper for energy-storage devices. Proceedings of the National Academy of Sciences of the United States of America 106:21490-21494, S21490/21491S21490/21413

Huang, H. \& Yang, X. (2004). Synthesis of polysaccharide-stabilized gold and silver nanoparticles: A green method. Carbohydr Res, Vol.339, pp.2627-2631 
Huang, H. \& Yang, Y. (2008) Preparation of silver nanoparticles in inorganic clay suspensions. Compos Sci Technol, Vol.68, pp.2948-2953

Huang, J.; Li, Q.; Sun. D.; Lu, Y.; Su, Y.; Yang, X.; Wang, H.; Wang, Y.; Shao, W.; He, N.; Hong, J. \& Chen, C. (2007). Biosynthesis of silver and gold nanoparticles by novel sundried Cinnamomum camphora leaf. Nanotechnology, Vol.18, pp.105,104

Huang, J.; Zhan, G.; Zheng, B.; Sun, D.; Lu, F.; Lin, Y.; Chen, H.; Zheng, Z.; Zheng, Y. \& Li, Q. (2011). Biogenic silver nanoparticles by Cacumen Platycladi extract: synthesis, formation mechanism and antibacterial activity. Ind Eng Chem Res, Vol.50, pp.90959106

Hussain, S.M.; Hess, K.L.; Gearhart, J.M.; Geiss, K.T. \& Schlager, J.J. (2005). In vitro toxicity of nanoparticles in BRL 3A rat liver cells. Toxicol in vitro, Vol.19, pp.975-983

Ingle, A.; Gade, A.; Pierrat, S.; Sönnichsen, C. \& Mahendra, R. (2008). Mycosynthesis of silver nanoparticles using the fungus Fusarium acuminatum and its activity against some human pathogenic bacteria. Current Nanoscience, Vol.4, pp.141-144

Iravani, S. (2011). Green synthesis of metal nanoparticles using plants. Green Chem, Vol.13, pp. 2638-2650.

Jacob, J.A.; Mahal, H.S.; Biswas, N.; Mukerjee, T. \& Kappor, S. (2008). Role of phenol derivatives in the formation of silver nanoparticles. Langmuir, Vol.24, pp.528-533

Jain, P. \& Pradeep, T. (2005). Potential of silver nanoparticle-coated polyurethane foam as an antibacterial water filter. Biotechnol Bioeng, Vol.90, pp.59-63

Ji, J.H.; Jung, J.H.; Kim, S.S.; Yoon, J.U.; Park, J.D.; Choi, B.S.; Chung, Y.H.; Kwon, I.H.; Jeong, J.; Han, B.S.; Shin, J.H.; Sung, J.H.; Song, K.S. \& Yu, I.J. (2007). Twenty-eightday inhalation toxicity study of silver nanoparticles in Sprague-Dawley rats. Inhal Toxicol, Vol.19, pp.857-871

Jia, X.; Ma, X.; Wei, D.; Dong, J. \& Qian, W. (2008). Direct formation of silver nanoparticles in cuttlebone-derived organic matrix for catalytic applications. Colloids Surf A:Physicochem Eng Aspects, Vol.330, pp.234-240

Jin, R.; Cao, Y.C.; Hao, E.; Metraux, G.S.; Schatz, G.C. \& Mirkin, C. (2003). Controlling anisotropic nanoparticle growth through plasmon excitation. Nature, Vol.425, pp.487-490

Johans, C.; Clohessy, J.; Fantini, S.; Kontturi, K. \& Cunnane, V.J. (2002). Electrosynthesis of polyphenylpyrrole coated silver particles at a liquid-liquid interface. Electrochemistry Communications, Vol.4, pp.227-230

Jung, J.; Oh, H.; Noh, H.; Ji, J. \& Kim, S. (2006). Metal nanoparticle generation using a small ceramic heater with a local heating area. J Aerosol Sci, Vol.37, pp.1662-1670

Kabashin, A.V. \& Meunier, M. (2003) Synthesis of colloidal nanoparticles during femtosecond laser ablation of gold in water. J Appl Phys, Vol.94, pp.7941-7943

Kalishwaralal, K.; Deepak, V.; Ramkumarpandian, S.; Bilal, M. \& Sangiliyandi G. (2008a). Biosynthesis of silver nanocrystals by Bacillus licheniformis. Colloids and Surfaces B: Biointerfaces, Vol.65, pp.150-153

Kalishwaralal, K.; Deepak, V.; Ramkumarpandian, S.; Nellaiah, H. \& Sangiliyandi, G. (2008b). Extracellular biosynthesis of silver nanoparticles by the culture supernatant of Bacillus licheniformis. Mater Lett, Vol.62, pp.4411-4413

Kasthuri, J.; Veerapandian, S. \& Rajendiran, N. (2009). Biological synthesis of silver and gold nanoparticles using apiin as reducing agent. Colloids and Surfaces B: Biointerfaces, Vol.68, pp.55-60 
Kasture, M.; Singh, S.; Patel, P.; Joy, P.A.; Prabhune, A.A.; Ramana, C.V. \& Prasad, B.L.V. (2007). Multiutility sophorolipids as nanoparticle capping agents: synthesis of stable and water dispersible Co nanoparticles. Langmuir, Vol.23, pp.11409-11412

Kathiresan, K.; Manivannan, S.; Nabeel, M.A. \& Dhivya, B. (2009). Studies on silver nanoparticles synthesized by a marine fungus, Penicillium fellutanum isolated from coastal mangrove sediment. Colloids and Surfaces B: Biointerfaces, Vol.71, pp.133-137

Kawasaki, M. \& Nishimura, N. (2006). 1064-nm laser fragmentation of thin Au and Ag flakes in acetone for highly productive pathway to stable metal nanoparticles. Appl Surf Sci, Vol.253, pp.2208-2216

Keating, C.D.; Kovaleski, K.K. \& Natan, M. (1998). Heightened electromagnetic fields between metal nanoparticles: surface enhanced Raman scattering from metalCytochrome c-metal sandwiches. J Phys Chem B, Vol.102, pp.9414

Kesharwani, J.; Yoon, K.Y.; Hwang, J. \& Rai, M. (2009). Phytofabrication of silver nanoparticles by leaf extract of Datura metel: hypothetical mechanism involvedin synthesis. Journal of Bionanoscience, Vol.3, pp.1-6

Kiesow, A.; Morris, J.E.; Radehaus, C. \& Heilmann, A. (2003). Switching behavior of plasma polymer films containing silver nanoparticles. J Appl Lett, Vol.94, pp.6988-6990

Kim, K.J.; Sung, W.S.; Moon, S.K.; Choi, J.S.; Kim, J.G. \& Lee, D.G. (2008). Antifungal effect of silver nanoparticles on dermatophytes. J Microbiol Biotechnol, Vol.18, pp.14821484

Kim, K.J.; Sung, W.S.; Suh, B.K.; Moon, S.K.; Choi, J.S.; Kim, J.G. \& Lee, D.G. (2009). Antifungal activity and mode of action of silver nano-particles on Candida albicans. Biometals, Vol.22, pp.235-242

Kim, S.; Yoo, B.; Chun, K.; Kang, W.; Choo, J.; Gong, M. \& Joo, S. (2005). Catalytic effect of laser ablated $\mathrm{Ni}$ nanoparticles in the oxidative addition reaction for a coupling reagent of benzylchloride and bromoacetonitrile. J Mol Catal A: Chem, Vol.226, pp.231-234

Kim, Y.S.; Kim, J.S.; Cho, H.S.; Rha, D.S.; Kim, J.M.; Park, J.D.; Choi, B.S.; Lim, R.; Chang, H.K.; Chung, Y.H.; Kwon, I.H.; Jeong, J.; Han, B.S. \& Yu, I.J. (2008). Twenty-eightday oral toxicity, genotoxicity, and gender-related issue distribution of silver nanoparticles in Sprague-Dawley rats. Inhal Toxicol, Vol.20, pp.575-583

Klaus-Joerger, T.; Joerger, R.; Olsson, E. \& Granqvist, C.G. (2001). Bacteria as workers in the living factory: metal-accumulating bacteria and their potential for materials science. Trends in Biotechnology, Vol.19, pp.15-20

Klaus, T.; Joerger, R.; Olsson, E. \& Granqvist, C.Gr. (1999). Silver-based crystalline nanoparticles, microbially fabricated. Proc Natl Acad Sci USA, Vol.96, pp.1361113614

Komarneni, S.; Li, D.; Newalkar, B.; Katsuki, H. \& Bhalla, A.S. (2002). Microwave-Polyol Process for Pt and Ag Nanoparticles. Langmuir, Vol.18, pp.5959-5962

Kora, A.J.; Sashidhar, R.B. \& Arunachalam, J. (2010). Gum kondagogu (Cochlospermum gossypium): A template for the green synthesis and stabilization of silver nanoparticles with antibacterial application. Carbohydrate Polymers, Vol.82, pp.670679

Korbekandi, H.; Iravani, S. \& Abbasi, S. (2009). Production of nanoparticles using organisms. Critical Reviews in Biotechnology, Vol.29, pp.279-306 
Kossyrev, P.; Yin, A.; Cloutier, S.; Cardimona, D.; Huang, D.; Alsing, P. \& Xu, J. (2005). Electric field tuning of plasmonic response of nanodot array in liquid crystal matrix. Nano Lett, Vol.5, pp.1978-1981

Kotthaus, S.; Gunther, B.H.; Hang, R. \& Schafer, H. (1997). Study of isotropically conductive bondings filled with aggregates of nano-sited Ag-particles. IEEE Trans Compon Packaging Technol, Vol.20, pp.15-20

Krishnaraj, C.; Jagan, E.G.; Rajasekar, S.; Selvakumar, P.; Kalaichelvan, P.T. \& Mohan, N. (2010). Synthesis of silver nanoparticles using Acalypha indica leaf extracts and its antibacterial activity against water borne pathogens. Colloids and Surfaces B: Biointerfaces, Vol.76, pp.50-56

Kruis, F.; Fissan, H. \& Rellinghaus, B. (2000). Sintering and evaporation characteristics of gas-phase synthesis of size-selected PbS nanoparticles. Mater Sci Eng B, Vol.69, pp.329-324

Krutyakov, Y.; Olenin, A.; Kudrinskii, A.; Dzhurik, P. \& Lisichkin, G. (2008). Aggregative stability and polydispersity of silver nanoparticles prepared using two-phase aqueous organic systems. Nanotechnol Russia, Vol.3, pp.303-310

Kumar, S.A.; Majid Kazemian, A.; Gosavi, S.W.; Sulabha, K.K.; Renu, P.;Ahmad A. \& Khan M.I. (2007). Nitrate reductase-mediated synthesis of silver nanoparticles from $\mathrm{AgNO}_{3}$. Biotechnology Letters, Vol.29, pp.439-445

Kumar, V.S.; Nagaraja, B.M.; Shashikala, V.; Padmasri, A.H.; Madhavendra, S.S. \& Raju, B.D. (2004). Highly efficient Ag/C catalyst prepared by electro-chemical deposition method in controlling microorganisms in water. J Mol Catal A, Vol.223, pp.313-319

Kvitek, L.; Panacek, A.; Soukupova, J.; Kolar, M.; Vecerova, R.; Prucek, R.; Holecová, M. \& Zbořil, R. (2008). Effect of surfactants and polymers on stability and antibacterial activity of silver nanoparticles (NPs). J Phys Chem C, Vol.112, pp.5825-5834

Kvítek, L.; Prucek, R.; Panáček, A.; Novotný, R.; Hrbác, J. \& Zbořil, R. (2005). The influence of complexing agent concentration on particle size in the process of SERS active silver colloid synthesis. J Mater Chem, Vol.15, pp.1099-1105

Lansdown, A.B. (2007). Critical observations on the neurotoxicity of silver. Crit Rev Toxicol, Vol.37, pp.237-250

Lee, H.Y.; Li, Z.; Chen, K.; Hsu, A.R.; Xu, C.; Xie, J.; Sun, S.; Chen, X. (2008). PET/MRI dualmodality tumor imaging using arginine-glycine-aspartic (RGD)-conjugated radiolabeled iron oxide nanoparticles, J Nucl Med, Vol.49, pp.1371-1379

Lengke, M.F.; Fleet, M.E. \& Southam, G. (2007). Biosynthesis of silver nanoparticles by filamentous cyanobacteria from a silver(I) nitrate complex. Langmuir, Vol.23, pp.2694-2699

Li, H.; Duan, X.; Liu, G. \& Liu, X. (2008). Photochemical synthesis and characterization of $\mathrm{Ag} / \mathrm{TiO}_{2}$ nanotube composites. J Mater Sci, Vol.43, pp.1669-1676

Li, Q.; Mahendra, S.; Lyon, D.; Brunet, L.; Liga, M.; Li, D. \& Alvarez, P. (2008). Antimicrobial nanomaterials for water disinfection and microbial control: Potential applications and implications. Water Res, Vol.42, pp.4591-4602

Lin, Y.E.; Vidic, R.D.; Stout, J.E.; McCartney, C.A. \& Yu V.L. (1998). Inactivation of Mycobacterium avium by copper and silver ions. Water Res, Vol.32, pp.1997-2000

Link, S.; Burda, C.; Nikoobakht, B. \& El-Sayed, M. (2000). Laser-induced shape changes of colloidal gold nanorods using femtosecond and nanosecond laser pulses. J Phys Chem B, Vol.104, pp.6152-6163 
Liu, P. \& Zhao, M. (2009). Silver nanoparticle supported on halloysite nanotubes catalyzed reduction of 4-nitrophenol (4-NP). Appl Surf Sci, Vol.255, pp.3989-3993

Liu, Y.; Wang, X.; Yang, F. \& Yang, X. (2008). Excellent antimicrobial properties of mesoporous anatase $\mathrm{TiO}_{2}$ and $\mathrm{Ag} / \mathrm{TiO}_{2}$ composite films. Microporous Mesoporous Mater, Vol.114, pp.431-439

Lok, C. (2006). Proteomic analysis of the mode of antibacterial action of silver nanoparticles. J Proteome Res, Vol.5, pp.916-924

Long, D.; Wu, G. \& Chen, S. (2007). Preparation of oligochitosan stabilized silver nanoparticles by gamma irradiation. Radiat Phys Chem, Vol.76, pp.1126-1131

Ma, H.; Yin, B.; Wang, S.; Jiao, Y.; Pan, W.; Huang, S.; Chen, S. \& Meng, F. (2004). Synthesis of silver and gold nanoparticles by a novel electrochemical method. Chem Phys Chem, Vol.24, pp.68-75

Ma, X-D.; Qian, X-F.; Yin, J. \& Zhu, Z-K. (2002). Preparation and characterization of polyvinyl alcohol-selenide nanocomposites at room temperature. J Mater Chem, Vol.12, pp.663-666

Macdonald, I.D.G. \& Smith, W. (1996). Orientation of Cytochrome c adsorbed on a citratereduced silver colloid surface. Langmuir, Vol.12, pp.706

Mafune, F.; Kohno, J.; Takeda, Y.; Kondow, T. \& Sawabe, H. (2001). Formation of gold nanoparticles by laser ablation in aqueous solution of surfactant. J Phys Chem B, Vol.105, pp.5114-5120

Mafune, F.; Kohno, J.; Takeda, Y.; Kondow, T. \& Sawabe, H. (2000). Structure and stability of silver nanoparticles in aqueous solution produced by laser ablation. J Phys Chem B, Vol.104, pp.8333-8337

Magnusson, M.; Deppert, K.; Malm, J.; Bovin, J. \& Samuelson, L. (1999). Gold nanoparticles: production, reshaping, and thermal charging. J Nanoparticle Res, Vol.1, pp.243-251

Maliszewska, I.; Szewczyk, K. \& Waszak, K. (2009). Biological synthesis of silver nanoparticles. Journal of Physics: Conference Series, Vol.146, pp.1-6

Malval, J-P.; Jin, M.; Balan, L.; Schneider, R.; Versace, D-L.; Chaumeil, H.; Defoin, A. \& Soppera, O. (2010). Photoinduced size-controlled generation of silver nanoparticles coated with carboxylate-derivatized thioxanthones. J Phys Chem C, Vol.114, pp.10396-10402

Manno, D.; Filippo, E.; Giulio, M. \& Serra, A. (2008). Synthesis and characterization of starch-stabilized Ag nanostructures for sensors applications. J Non-Cryst Solids, Vol.354, pp.5515-5520

Mansur, H.S.; Grieser, F.; Marychurch, M.S.; Biggs, S.; Urquhart, R.S. \& Furlong, D. (1995). Photoelectrochemical properties of 'q-state' cds particles in arachidic acid langmuirblodgett films. J Chem Soc Faraday Trans, Vol.91, pp.665-672

Mantion, A.; Guex, A.G.; Foelske, A.; Mirolo, L.; Fromn, K.M. \& Painsi, M. (2008). Silver nanoparticle engineering via oligovaline organogels. Soft Matter, Vol.4, pp.606-617

Merga, G.; Wilson, R.; Lynn, G.; Milosavljevic, B. \& Meisel, D. (2007). Redox catalysis on "naked" silver nanoparticles. J Phys Chem C, Vol.111, pp.12220-12226

Mohan, Y.M.; Raju, K.M.; Sambasivudu, K.; Singh, S. \& Sreedhar, B. (2007). Preparation of acacia-stabilized silver nanoparticles: A green approach. J Appl Polym Sci, Vol.106, pp.3375-3381

Mokhtari, N.; Daneshpajouh, S.; Seyedbagheri, S.; Atashdehghan, R.; Abdi, K.; Sarkar, S.; Minaian, S.; Shahverdi, H.R. \& Shahverdi, A.R. (2009). Biological synthesis of very 
small silver nanoparticles by culture supernatant of Klebsiella pneumonia: The effects of visible-light irradiation and the liquid mixing process. Materials Research Bulletin, Vol.44, pp.1415-1421

Morones, J.R.; Elechiguerra, L.J.; Camacho, A.; Holt, K.; Kouri, B.J.; Ramirez, T.J. \& Yocaman, J.M. (2005). The bactericidal effect of silver nanoparticles. Nanotechnology, Vol.16, pp.2346-2353

FU, M.; Li Q.; Sun, D.; Lu, Y.; He, N.; Xu, D.; Wang, H. \& Huang, J. (2006). Rapid preparation process of silver nanoparticles by bioreduction and their characterizations. Chinese J Chem Eng, Vol.14, pp.114-117

Nair, B. \& Pradeep, T. (2002). Coalescence of nanoclusters and formation of submicron crystallites assisted by Lactobacillus strains. Crystal Growth $\mathcal{E}$ Design, Vol.2, pp.293298

Navaladian, S.; Viswanathan, B.; Varadarajan, T.K. \& Viswanath, R.P. (2008). Microwaveassisted rapid synthesis of anisotropic $\mathrm{Ag}$ nanoparticles by solid state transformation. Nanotechnology, Vol.19, pp.045603

Nino-Martinez, N.; Martinez-Castanon, G.A.; Aragon-Pina, A.; Martinez-Gutierrez, F.; Martinez-Mendoza, J.R. \& Ruiz, F. (2008). Characterization of silver nanoparticles synthesized on titanium dioxide fine particles. Nanotechnology, Vol.19, pp.065711/065711-065711/065718

Oliveira, M.; Ugarte, D.; Zanchet, D. \& Zarbin, A. (2005). Influence of synthetic parameters on the size, structure, and stability of dodecanethiol-stabilized silver nanoparticles. J Colloid Interface Sci, Vol.292, pp.429-435

Pal, S.; Tak, Y.K. \& Song, J.M. (2007). Does the antibacterial activity of silver nanoparticles depend on the shape of the nanoparticle? a study of the gram-negative bacterium Escherichia coli. Applied and Environmental Microbiology, Vol.73, pp.1712-1720

Panacek, A.; Kvitek, L.; Prucek, R.; Kolar, M.; Vecerova, R.; Pizurova, N.; Sharma, V.K.; Nevěná, T. \& Zbořil, R. (2006). Silver colloid nanoparticles: synthesis, characterization, and their antibacterial activity. J Phys Chem B, Vol.110, pp.1624816253

Park, S.; Lee, Y.K.; Jung, M.; Kim, K.H.; Eun-Kyung Ahn, N.C.; Lim, Y. \& Lee, K.H. (2007). Cellular toxicity of various inhalable metal nanoparticles on human alveolar epithelial cells. Inhalat Toxicol, Vol.19, pp.59-65

Pillai, Z.S. \& Kamat, P.V. (2004). What factors control the size and shape of silver nanoparticles in the citrate ion reduction method?. J Phys Chem B, Vol.108, pp.945951

Pissuwan, D.; Valenzuela, S.M. \& Cortie, M.B. (2006). Therapeutic possibilities of plasmonically heated gold nanoparticles, Trends Biotechnol, Vol.24, pp.62-67

Prasad, T.N.V.K.V. \& Elumalai, E. (2011). Biofabrication of Ag nanoparticles using Moringa oleifera leaf extract and their antimicrobial activity. Asian Pacific Journal of Tropical Biomedicine, Vol.1, pp.439-442

Ramnami, S.P.; Biswal, J. \& Sabharwal, S. (2007). Synthesis of silver nanoparticles supported on silica aerogel using gamma radiolysis. Radiat Phys Chem, Vol.76, pp.1290-1294

Raveendran. P.; Fu, J. \& Wallen, S.L. (2003). Completely "green" synthesis and stabilization of metal nanoparticles. J Am Chem Soc, Vol.125, pp.13940-13941

Raveendran, P.; Fu, J. \& Wallen, S.L. (2005). A simple and "green" method for the synthesis of $\mathrm{Au}, \mathrm{Ag}$, and $\mathrm{Au}-\mathrm{Ag}$ alloy nanoparticles, Green Chem, Vol.8, pp.34-38 
Ravindra, S.; Murali Mohan, Y.; Narayana Reddy, N. \& Raju, K.M. (2010). Fabrication of antibacterial cotton fibres loaded with silver nanoparticles via "Green Approach". Colloids and Surfaces A: Physicochem Eng Aspects, Vol.367, pp.31-40

Rifai, S.; Breen, C.A.; Solis, D.J. \& Swager, T.M. (2006). Facile in situ silver nanoparticle formation in insulating porous polymer matrices. Chem Mater,Vol.18, pp.21-25

Roe, D.; Karandikar, B.; Bonn-Savage, N.; Gibbins, B. \& Roullet, J.B. (2008). Antimicrobial surface functionalization of plastic catheters by silver nanoparticles. J Antimicrob Chemother, Vol.61, pp.869-876

Sadowski, Z.; Maliszewska, I.H.; Grochowalska, B.; Polowczyk, I. \& Kozlecki, T. (2008). Synthesis of silver nanoparticles using microorganisms. Materials Science-Poland, Vol.26, pp.419-424

Safaepour, M.; Shahverdi, A.R.; Shahverdi, H.R.; Khorramizadeh, M.R. \& Gohari, A.R. (2009). Green synthesis of small silver nanoparticles using geraniol and its cytotoxicity against Fibrosarcoma-Wehi 164. Avicenna J Med Biotech, Vol.1, pp.111115

Saifuddin, N.; Wong, C.W. \& Nur Yasumira, A.A. (2009). Rapid biosynthesis of silver nanoparticles using culture supernatant of bacteria with microwave irradiation. EJournal of Chemistry, Vol.6, pp.61-70

Sakamoto, M.; Fujistuka, M. \& Majima, T. (2009). Light as a construction tool of metal nanoparticles: synthesis and mechanism. J Photochem and Photobiol C: Photochem Reviews, Vol.10, pp.33-56

Sakamoto, M.; Tachikawa, T.; Fujitsuka, M. \& Majima, T. (2007). Photochemical formation of $\mathrm{Au} / \mathrm{Cu}$ bimetallic nanoparticles with different shapes and sizes in a PVA film. Adv Funct Mater, Vol.17, pp.857-862

Sanghi, R. \& Verma P. (2009). Biomimetic synthesis and characterisation of protein capped silver nanoparticles. Bioresource Technology, Vol.100, pp.501-504

Santhoshkumar, T.; Rahuman, A.A.; Rajakumar, G.; Marimuthu, S.; Bagavan, A.; Jayaseelan, C.; Zahir, A.A.; Elango, G. \& Kamaraj, C. (2010). Synthesis of silver nanoparticles using Nelumbo nucifera leaf extract and its larvicidal activity against malaria and filariasis vectors. Parasitol Res, Vol.108, pp.693-702

Sarkar, A.; Kapoor, S. \& Mukherjee, T. (2005). Preparation, characterization, and surface modification of silver nanoparticles in formamide. J Phys Chem, Vol.109, pp.76987704

Sastry, M.; Ahmad, A.; Khan, M.I. \& Kumar, R. (2003). Biosynthesis of metal nanoparticles using fungi and actinomycete. Current Science, Vol.85, pp.162-170

Sathishkumar, M.; Sneha, K.; Won, S.W.; Cho, C-W.; Kim, S. \& Yun, Y.S. (2009). Cinnamon zeylanicum bark extract and powder mediated green synthesis of nano-crystalline silver particles and its bactericidal activity. Colloids and Surfaces B: Biointerfaces, Vol.73, pp.332-338

Schmaehl, D. \& Steinhoff, D. (1960). Studies on cancer induction with colloidal silver and gold solutions in rats. Z Krebsforsch, Vol.63, pp.586-591

Schmid, G. (1992). Large clusters and colloids. Metals in the embryonic state. Chem Rev, Vol.92, pp.1709-1727

Seery, M.K.; George, R.; Floris, P. \& Pillai, S.C. (2007). Silver doped titanium dioxide nanomaterials for enhanced visible light photocatalysis. J Photochem Photobiol A Chem, Vol.189, pp.258-263 
Senapati, S. (2005). Biosynthesis and immobilization of nanoparticles and their applications. University of pune, India

Shahverdi, A.R.; Minaeian, S.; Shahverdi, H.R.; Jamalifar, H. \& Nohi, A. (2007). Rapid synthesis of silver nanoparticles using culture supernatants of Enterobacteria: A novel biological approach. Process Biochemistry, Vol.42, pp.919-923

Shahverdi, R.A.; Fakhimi, A.; Shahverdi, H.R. \& Minaian, S. (2007). Synthesis and effect of silver nanoparticles on the antibacterial activity of different antibiotics against Staphyloccocus aureus and Escherichia coli. Nanomed: Nanotechnol Biol Med, Vol.3, pp.168-171

Shankar, S.S.; Absar, A. \& Murali, S. (2003). Geranium leaf assisted biosynthesis of silver nanoparticles. Biotechnol Prog, Vol.19, pp.1627-1631

Shankar, S.S.; Rai, A.; Ankamwar, B.; Singh, A.; Ahmad, A. \& Sastry, M. (2004). Biological synthesis of triangular gold nanoprisms. Nature Materials, Vol.3, pp.482-488

Shanmukh, S.; Jones, L.; Driskell, J.; Zhao, Y.; Dluhy, R. \& Tripp, R.A. (2006). Rapid and sensitive detection of respiratory virus molecular signatures using a silver nanorod array SERS substrate. Nano Letters, Vol.6, pp.2630-2636

Sharma, V.K.; Yngard, R.A. \& Lin, Y. (2009). Silver nanoparticles: green synthesis and their antimicrobial activities. Advances in Colloid and Interface Science, Vol.145, pp.83-96

Shchukin, D.G.; Radtchenko, I.L. \& Sukhorukov, G. (2003). Photoinduced reduction of silver inside microscale polyelectrolyte capsules. Chem Phys Chem, Vol.4, pp.1101-1103

Shin, S.H.; Ye, M.K.; Kim, H.S. \& Kang, H.S. (2007). The effects of nanosilver on the proliferation and cytokine expression by peripheral blood mononuclear cells. Int Immuno pharmacol, Vol.7, pp.1813-1818

Si, S. \& Mandal, T.K. (2007). Tryptophan-based peptides to synthesize gold and silver nanoparticles: a mechanistic and kinetic study. Chem A Eur J, Vol.13, pp.3160-3168

Šileikaitè, A.; Puišo, J.; Prosyčevas, I.; Guobienè, A.; Tamulevičius, S.; Tamulevičius, T. \& Janušas, G. (2007). Polymer diffraction gratings modified with silver nanoparticles. Materials Science (Medžiagotyra), Vol.13, pp.273-277

Singhal, G.; Bhavesh, R.; Kasariya, K.; Sharma, A.R. \& Singh, R.P. (2011). Biosynthesis of silver nanoparticles using Ocimum sanctum (Tulsi) leaf extract and screening its antimicrobial activity. J Nanopart Res, Vol.13, pp.2981-2988

Slawson, R.M.; Van, D.M.; Lee, H. \& Trevor, J. (1992). Germanium and silver resistance, accumulation and toxicity in microorganisms. Plasmid, Vol.27, pp.73-79

Socol, Y.; Abramson, O.; Gedanken, A.; Meshorer, Y.; Berenstein, L. \& Zaban, A. (2002). Suspensive electrode formation in pulsed sonoelectrochemical synthesis of silver nanoparticles. Langmuir, Vol.18, pp.4736-4740

Song, J.Y. \& Kim, B. (2008). Rapid biological synthesis of silver nanoparticles using plant leaf extracts. Bioprocess Biosyst Eng, Vol.32, pp.79-84

Soroushian, B.; Lampre, I.; Belloni, J. \& Mostafavi, M. (2005). Radiolysis of silver ion solutions in ethylene glycol: solvated electron and radical scavenging yields. Radiat Phys Chem, Vol.72, pp.111-118

Soto, K.; Garza, K.M. \& Murr, L.E. (2007). Cytotoxic effects of aggregated nanomaterials. Acta Biomater, Vol.3, pp.351-358

Soto, K.F.; Carrasco, A.; Powell, T.G.; Garza, K.M. \& Murr, L.E. (2005). Comparative in vitro cytotoxicity assessment of some manufactured nanoparticulate materials 
characterized by transmission electron microscopy. J Nanopart Res, Vol.7, pp.145169

Soukupova, J.; Kvitek, L.; Panacek, A.; Nevecna, T. \& Zboril, R. (2008). Comprehensive study on surfactant role on silver nanoparticles (NPs) prepared via modified Tollens process. Mater Chem Phys, Vol.111, pp.77-81

Sreeram, K.J.; M N. \& Nair, B.U. (2008). Microwave assisted template synthesis of silver nanoparticles. Bull Mater Sci, Vol.31, pp.937-942

Su, H.L.; Chou, C.C.; Hung, D.J.; Lin, S.H.; Pao, I.C.; Lin, J.H.; Huang, F.L.; Dong, R.X. \& Lin, J.J. (2009). The disruption of bacterial membrane integrity through ROS generation induced by nanohybrids of silver and clay. Biomaterials, Vol.30, pp.5979-5987

Sudeep, P.K. \& Kamat, P.V. (2005). Photosensitized growth of silver nanoparticles under visible light irradiation: a mechanistic investigation. Chem Mater, Vol.17, pp.54045410

Sun, R.W.; Chen, R.; Chung, N.P.; Ho, C.M.; Lin, C.L. \& Che, C.M. (2005). Silver nanoparticles fabricated in Hepes buffer exhibit cytoprotective activities toward HIV-1 infected cells. Chem Commun, Vol.40, pp.5059-5061

Sung, J.H.; Ji, J.H.; Yoon, J.U.; Kim, D.S.; Song, M.Y.; Jeong, J.; Han, B.S.; Han, J.H.; Chung, Y.H.; Kim, J.; Kim, T.S.; Chang, H.K.; Lee, E.J.; Lee, J,H. \& Yu, I.J. (2008). Lung function changes in Sprague-Dawley rats after prolonged inhalation exposure to silver nanoparticles. Inhal Toxicol, Vol.20, pp.567-574

Sylvestre, J.P.; Kabashin, A.V.; Sacher, E.; Meunier, M. \& Luong, J.H.T. (2004). Stabilization and size control of gold nanoparticles during laser ablation in aqueous cyclodextrins. J Am Chem Soc, Vol.126, pp.7176-7177

Tai, C.; Wang, Y-H. \& Liu, H.S. (2008). A green process for preparing silver nanoparticles using spinning disk reactor. AIChE J, Vol.54, pp.445-452

Takenaka, S.; Karg, E.; Roth, C.; Schulz, H.; Ziesenis, A.; Heinzmann, U.; Schramel, P. \& Heyder, J. (2001). Pulmonary and systemic distribution of inhaled ultrafine silver particles in rats. Environ Health Perspect, Vol.109, pp.547-551

Tan, M.; Wang, G.; Ye, Z. \& Yuan, J. (2006). Synthesis and characterization of titania-based monodisperse fluorescent europium nanoparticles for biolabeling, Journal of Luminescence, Vol.117, pp.20-28

Tarasenko, N.; Butsen, A.; Nevar, E. \& Savastenko, N. (2006). Synthesis of nanosized particles during laser ablation of gold in water. Appl Surf Sci, Vol.252, pp.4439-4444

Trop, M.; Novak, M.; Rodl, S.; Hellbom, B.; Kroell, W. \& Goessler, W. (2006). Silver coated dressing acticoat caused raised liver enzymes and argyria-like symptoms in burn patient. J Trauma Injury Infect Crit Care, Vol.60, pp.648-652

Troupis, A.; Hiskia, A. \& Papaconstantinou, E. (2002). Synthesis of metal nanoparticles by using polyoxometalates as photocatalysts and stabilizers. Angew Chem Int Ed, Vol.41, pp.1911-1914

Tsuji, M.; Matsumoto, K.; Jiang, P.; Matsuo, R.; Hikino, S.; Tang, X-L. \& Nor Kamarudin, K.S. (2008). The Role of Adsorption Species in the Formation of Ag Nanostructures by a Microwave-Polyol Route. Bull Chem Soc Jpn, Vol.81, pp.393-400

Tsuji, T.; Iryo, K.; Watanabe, N. \& Tsuji, M. (2002). Preparation of silver nanoparticles by laser ablation in solution: influence of laser wavelength on particle size. Appl Surf Sci, Vol.202, pp.80-85 
Tsuji, T.; Kakita, T. \& Tsuji, M. (2003). Preparation of nano-Size particle of silver with femtosecond laser ablation in water. Applied Surface Science, Vol.206, pp.314-320

Veerasamy, R.; Xin, T.Z.; Gunasagaran, S.; Xiang, T.F.W.; Yang, E.F.C.; Jeyakumar, N. \& Dhanaraj. S.A. (2011). Biosynthesis of silver nanoparticles using mangosteen leaf extract and evaluation of their antimicrobial activities. Journal of Saudi Chemical Society, Vol.15, pp.113-120

Vigneshwaran, N.; Ashtaputre, N.M.; Varadarajan, P.V.; Nachane, R.P.; Paralikar, K.M. \& Balasubramanya, R. (2007). Biological synthesis of silver nanoparticles using the fungus Aspergillus flavus. Materials Letters, Vol.61, pp.1413-1418

Vigneshwaran, N.; Kathe, A.A.; Varadarajan, P.V.; Nachane, R.P. \& Balasubramanya, R. (2006a). Biomimetics of silver nanoparticles by white rot fungus, Phaenerochaete chrysosporium. Colloids and Surfaces B: Biointerfaces, Vol.53, pp.55-59

Vigneshwaran, N.; Nachane, R.P.; Balasubramanya, R.H. \& Varadarajan, P.V. (2006b). A novel one-pot 'green' synthesis of stable silver nanoparticles using soluble starch. Carbohydr Res, Vol.341, pp.2012-2018

Vilchis-Nestor, A.R.; Sánchez-Mendieta, V.; Camacho-López, M.A.; Gómez-Espinosa, R.M.; Camacho-López, M.A. \& Arenas-Alatorre, J. (2008). Solventless synthesis and optical properties of $\mathrm{Au}$ and $\mathrm{Ag}$ nanoparticles using Camellia sinensis extract. Materials Letters, Vol.62, pp.3103-3105

Wang, Y. \& Herron, N. (1991). Nanometer-sized semiconductor clusters: materials synthesis, quantum size effects, and photophysical properties. J Phys Chem, Vol.95, pp.525-532

Wei, H.; Li, J.; Wang, Y. \& Wang, E. (2007). Silver nanoparticles coated with adenine: preparation, self-assembly and application in surface-enhanced Raman scattering. Nanotechnology, Vol.18, pp.175610

Wiley, B.; Sun, Y.; Mayers, B. \& Xi, Y. (2005). Shape-controlled synthesis of metal nanostructures: the case of silver. Chem Eur J, Vol.11, pp.454-463

Wu, Q.; Cao, H.; Luan, Q.; Zhang, J.; Wang, Z.; Warner, J-H. \& Watt, A.A.R. (2008). Biomolecule-assisted synthesis of water-soluble silver nanoparticles and their biomedical applications. Inorg Chem, Vol.47, pp.5882-5888

Yang, L.; Shen, Y.; Xie, A. \& Zhang, B. (2007). Facile size-controlled synthesis of silver nanoparticles in UV-irradiated tungstosilicate acid solution. J Phys Chem C, Vol.111, pp.5300-5308

Yin, H.; Yamamoto, T.; Wada, Y. \& Yanagida, S. (2004). Large-scale and size-controlled synthesis of silver nanoparticles under microwave irradiation. Materials Chemistry and Physics, Vol.83, pp.66-70

Yin, Y.; Li, Z-Y.; Zhong, Z.; Gates, B. \& Venkateswaran, S. (2002). Synthesis and characterization of stable aqueous dispersions of silver nanoparticles through the Tollens process. J Mater Chem, Vol.12, pp.522-527

Yoon, K.Y.; Byeon, J.H.; Park, J.H. \& Hwang, J. (2007). Susceptibility constrants of Escherichia coli and Bacillus subtilis to silver and copper nanoparticles. Science of the Total Environment, Vol.373, pp.572-575

Yu, H.; Xu, X.; Chen, X.; Lu, T.; Zhang, P. \& Jiang, X. (2007). Preparation and antibacterial effects of PVA-PVP hydrogels containing silver nanoparticles. J Appl Polym Sci, Vol.103, pp.125-133 
Zhang, G.; Keita, B.; Dolbecq, A.; Mialane, P.; Secheresse, F.; F M. \& Nadjo, L. (2007). Green chemistry-type one-step synthesis of silver nanostructures based on $\mathrm{MoV}^{\mathrm{V}} \mathrm{MoVI}$ mixed-valence polyoxometalates. Chem Mater, Vol.19, pp.5821-5823

Zhang, L.; Yu, J.C.; Yip, H.Y.; Li, Q.; Kwong, K.W.; A-W X. \& Wong, P.K. (2003). Ambient light reduction strategy to synthesize silver nanoparticles and silver-coated $\mathrm{TiO}_{2}$ with enhanced photocatalytic and bactericidal activities. Langmuir, Vol.19, pp.10372-10380

Zhang, W.; Qiao, X. \& Chen, J. (2007). Synthesis of nanosilver colloidal particles in water/oil microemulsion. Colloids Surf A: Physicochem Eng Aspects, Vol.299, pp.22-28

Zhang, W. \& Wang, G. (2003). Research and development for antibacterial materials of silver nanoparticle. New Chem Mater, Vol.31, pp.42-44

Zhang, Y.; Chen, F.; Zhuang, J.; Tang, Y.; Wang, D.; Wang, Y.; Dong, A. \& Ren, N. (2002). Synthesis of silver nanoparticles via electrochemical reduction on compact zeolite film modified electrodes. Chemical Communications, Vol.24, pp.2814-2815

Zhang, Y.; Peng, H.; Huang, W.; Zhou, Y. \& Yan, D. (2008). Facile preparation and characterization of highly antimicrobial colloid Ag or Au nanoparticles. J Colloid Interface Sci, Vol.325, pp.371-376

Zhang, Z. \& Han, M. (2003). One-step preparation of size-selected and well-dispersed silver nanocrystals in polyacrylonitrile by simultaneous reduction and polymerization. $J$ Mater Commun, Vol.13, pp.641-643

Zharov, V.P.; Kim, J-W.; Curiel, D.T. \& Everts, M. (2005). Self-assembling nanoclusters in living systems: application for integrated photothermal nanodiagnostics and nanotherapy. Nanomedicine: Nanotechnology, Biology and Medicine, Vol.1, pp.326-345

Zheng, J.; Hua, Y.; Xinjun, L. \& Shanqing, Z. (2008). Enhanced photocatalytic activity of $\mathrm{TiO}_{2}$ nano-structured thin film with a silver hierarchical configuration. Appl Surf Sci, Vol.254, pp.1630-1635

Zhong, L.; Hu, J.; Cui, Z.; Wan, L. \& Song, W. (2007). In-Situ loading of noble metal nanoparticles on hydroxyl-group-rich titania precursor and their catalytic applications. Chem Mater, Vol.19, pp.4557-4562

Zhou, Y.; Yu, S.H.; Wang, C.Y.; Li, X.G.; Zhu, Y.R. \& Chen, Z.Y. (1999). A novel ultraviolet irradiation photoreduction technique for the preparation of single-crystal Ag nanorods and Ag dendrites. Advanced Materials, Vol.11, pp.850-852

Zhu, S.; Du, C.L. \& Fu, Y. (2009). Fabrication and characterization of rhombic silver nanoparticles for biosensing. Optical Materials, Vol.31, pp.769-774 


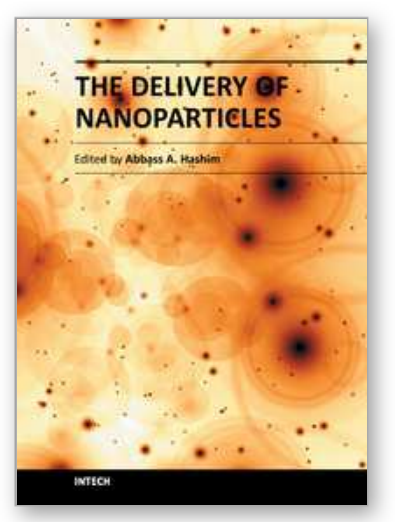

\author{
The Delivery of Nanoparticles \\ Edited by Dr. Abbass A. Hashim
}

ISBN 978-953-51-0615-9

Hard cover, 540 pages

Publisher InTech

Published online 16, May, 2012

Published in print edition May, 2012

Nanoparticle is a general challenge for today's technology and the near future observations of science. Nanoparticles cover mostly all types of sciences and manufacturing technologies. The properties of this particle are flying over today scientific barriers and have passed the limitations of conventional sciences. This is the reason why nanoparticles have been evaluated for the use in many fields. InTech publisher and the contributing authors of this book in nanoparticles are all overconfident to invite all scientists to read this new book. The book's potential was held until it was approached by the art of exploring the most advanced research in the field of nano-scale particles, preparation techniques and the way of reaching their destination. 25 reputable chapters were framed in this book and there were alienated into four altered sections; Toxic Nanoparticles, Drug Nanoparticles, Biological Activities and Nano-Technology.

\title{
How to reference
}

In order to correctly reference this scholarly work, feel free to copy and paste the following:

Hassan Korbekandi and Siavash Iravani (2012). Silver Nanoparticles, The Delivery of Nanoparticles, Dr. Abbass A. Hashim (Ed.), ISBN: 978-953-51-0615-9, InTech, Available from: http://www.intechopen.com/books/the-delivery-of-nanoparticles/silver-nanoparticles

\section{INTECH}

open science | open minds

\section{InTech Europe}

University Campus STeP Ri

Slavka Krautzeka 83/A

51000 Rijeka, Croatia

Phone: +385 (51) 770447

Fax: +385 (51) 686166

www.intechopen.com

\section{InTech China}

Unit 405, Office Block, Hotel Equatorial Shanghai

No.65, Yan An Road (West), Shanghai, 200040, China 中国上海市延安西路65号上海国际贵都大饭店办公楼 405 单元

Phone: +86-21-62489820

Fax: +86-21-62489821 
(C) 2012 The Author(s). Licensee IntechOpen. This is an open access article distributed under the terms of the Creative Commons Attribution 3.0 License, which permits unrestricted use, distribution, and reproduction in any medium, provided the original work is properly cited. 